\title{
On the evolution of programmed cell death: apoptosis of the unicellular eukaryote Leishmania major involves cysteine proteinase activation and mitochondrion permeabilization
}

\author{
D Arnoult ${ }^{1}, K_{\text {Akarid }}{ }^{1,2}$, A Grodet $^{3}$, PX Petit ${ }^{4}$, J Estaquier $^{1}$ and \\ JC Ameisen*,1 \\ ${ }^{1}$ EMI-U 9922 INSERM-Universite Paris 7, IFR 02, AP-HP, Hopital Bichat-Claude \\ Bernard, 46, rue Henri Huchard, 75877 Paris cedex 18, France \\ 2 Department de Biologie, Faculte des Sciences d'El Jadida, Morocco \\ 3 INSERM U327, IFR 02, Faculte de Medecine Xavier Bichat, 16, rue Henri \\ Huchard, 75018 Paris, France \\ 4 INSERUM U129, Institut Cochin de Genetique Moléculaire, 24, rue du Fg St- \\ Jacques, 75014 Paris, France \\ * Corresponding author: JC Ameisen, INSERM EMI-U 9922, CHU Bichat-Claude \\ Bernard, 46 rue Henri Huchard, 75877 Paris cedex 18, France. \\ Tel: +33 1402586 01; Fax: +331402586 02; E-mail: ants@club-internet.fr
}

Received 13.6.01; revised 31.8.01; accepted 31.8.01

Edited by G Melino

\begin{abstract}
Leishmania major is a protozoan parasite from one of the most ancient phylogenic branches of unicellular eukaryotes, and containing only one giant mitochondrion. Here we report that staurosporine, that induces apoptosis in all mammalian nucleated cells, also induces in L. major a death process with several cytoplasmic and nuclear features of apoptosis, including cell shrinkage, phosphatidyl serine exposure, maintenance of plasma membrane integrity, mitochondrial transmembrane potential $(\Delta \Psi \mathrm{m})$ loss and cytochrome $c$ release, nuclear chromatin condensation and fragmentation, and DNA degradation. Nuclear apoptosis-like features were prevented by cysteine proteinase inhibitors, and cell free assays using dying $L$. major cytoplasmic extracts indicated that the cysteine proteinases involved (i) also induced nuclear apoptosis-like features in isolated mammalian nuclei, and (ii) shared at least two nuclear substrates, but no cleavage site preference, with human effector caspases. Finally, isolated L. major mitochondria released cytochrome $c$ and cysteine proteinases with nuclear pro-apoptotic activity when incubated with human recombinant Bax, even (although much less efficiently) when Bax was deleted of its transmembrane domain required for insertion in mitochondrial outermembranes, implying that $L$. major mitochondrion may express proteins able to interact with Bax. The recruitment of cysteine proteinases and mitochondria to the cell death machinery may be of very ancient evolutionary origin. Alternately, host/ parasite interactions may have exerted selective pressures on the cell death phenotype of kinetoplastid parasites, resulting in the more recent emergence of an apoptotic machinery through a process of convergent evolution.
\end{abstract}

Cell Death and Differentiation (2002) 9, 65-81. DOI: 10.1038/sj/ cdd/4400951

Keywords: Leishmania major; cell death; apoptosis; mitochondria; DNA fragmentation; cysteine proteinase; (cytochrome $c$; Bax; evolution; unicellular eukaryote)

Abbreviations: $\mathrm{BAF}, \mathrm{Boc}-\mathrm{Asp}(\mathrm{OMe})-\mathrm{CH}_{2} \mathrm{~F} ; \mathrm{E} 64$, trans-Epoxysuccinyl-L-Leucylamido-(4-Guanido)Butane; AIF, Apoptosis Inducing Factor; CAD, Caspase Activated Dnase; $\Delta \Psi \mathrm{m}$, mitochondrial transmembrane potential; ICAD, Inhibitor of Caspase Activated Dnase; PARP, Poly(ADP-ribose) polymerase

\section{Introduction}

Programmed cell death (PCD) or apoptosis is a genetically regulated physiological process of cell suicide that is central to the development and homeostasis of multicellular organisms. ${ }^{1-4}$ Crucial features of PCD appear to be conserved in nematodes (Caenorhabditis elegans), insects (Drosophila melanogaster) and vertebrates (mammals) in terms of both the genes encoding the basic cell death machinery, and the morphological and biochemical features of apoptosis, the most frequent phenotype of PCD. ${ }^{1-5}$

In mammalian cells, PCD depends on two major executionary pathways that usually operate together and amplify each other. One involves the proteolytic activation of a family of aspartate-directed cysteine proteinases, the caspases; ${ }^{4,6,7}$ the other one involves mitochondrial outer membrane permeabilization, regulated by members of the $\mathrm{Bcl}-2 / \mathrm{Bax}$ protein family, $3,8-10$ and leading to the release into the cytosol of mitochondrial intermembrane space proteins that either induce activation of the caspase pathway, such as cytochrome $c$ and Smac/Diablo, or favor the induction of caspase-independent executionary pathways, such as AIF.

In mammalian cells, while caspase activity is essential for the induction of the typical nuclear features of apoptosis, such as chromatin fragmentation and internucleosomal DNA fragmentation, it is dispensable, in several instances, for the induction and execution of PCD. ${ }^{11-16}$ In contrast, the requirement for caspase activation appears crucial for the execution of PCD in the invertebrates $C$. elegans and $D$. melanogaster ${ }^{3-5}$ suggesting that the recruitment of caspases and mitochondrial effectors to the cell suicide machinery may have been subjected to phylogenic variation during metazoan evolution, and that the caspase cysteine proteinases may represent the initial ancestral effectors involved in PCD. The evolutionary origin of PCD, however, predates that of the metazoan. ${ }^{17}$ 
nucleated cells studied so arr $^{35}$ also induces in L. major a death process that has most nuclear and cytoplasmic features of mammalian cells apoptosis. Our findings suggest that part at least of the apoptotic machinery operating in $L$. major involves both cysteine proteinases and the mitochondrion, and therefore shares similarities with the apoptotic machinery operating in mammalian cells.

\section{Results}

\section{Staurosporine-induced $L$. major cell death is associated with several nuclear and cytoplasmic features of apoptosis}

L. major promastigotes, when suspended in fresh conditioned medium at a temperature of $27^{\circ} \mathrm{C}$ (the temperature of theirinsect vector), proliferate rapidly in axenic cultures, leading, in a few days, to an exponential increase in promastigote numbers. As shown in Figure 1, the broad protein kinase inhibitor staurosporine $(4 \mu \mathrm{M})$, that induces apoptosis in all nucleated mammalian cells, ${ }^{35}$ induced in L. major promastigotes a rapid cell death process that led, within 5 days, to the disappearance of almostall the promastigotes from the culture. Moreover, when the few remaining cells were washed and resuspended in fresh medium, no culture of proliferating promastigotes could be recovered (data not shown). Using flow cytometry analysis, we then investigated the phenotype of this cell death process. Culture for $24 \mathrm{~h}$ with staurosporine induced promastigote cell shrinkage (Figure 2a), phosphatidyl serine (PS) exposure at the outer cell surface (Figure $2 b$ ), mitochondrial transmembrane potential $(\Delta \Psi \mathrm{m})$ disruption (Figure $2 \mathrm{c}$ ) and nuclear DNA degradation (Figure 2d). Two of the major characteristic features of mammalian cell apoptosis, that distinguishes it from the passive and chaotic destruction process of necrosis, are cell shrinkage and maintenance of plasma membrane impermeability. ${ }^{1,4,34,36}$ For example, propidium iodide $(\mathrm{PI})$, when used in the absence of cell permeant, does not stain apoptotic cells, but enters and stains necrotic cells, whose plasma membrane is damaged (see for example Ref. ${ }^{15}$ ). Promastigotes incubated

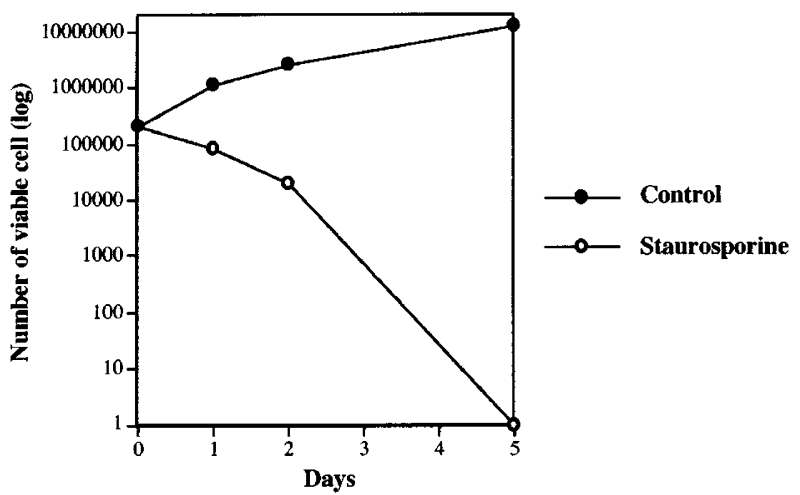

Figure 1 Staurosporine induces $L$. major promastigote cell death. $L$. major promastigotes $\left(10^{5} / \mathrm{ml}\right)$ were incubated in the absence (Control) or presence (staurosporine) of staurosporine $(4 \mu \mathrm{M})$ for 4 days and absolute numbers of living cells (longiform and mobile cells) were counted during 5 days. Round and shrunk cells were considered as dead or dying cells. The results shown are representative of two independent experiments 
for $24 \mathrm{~h}$ with staurosporine were not labeled by $\mathrm{PI}$, while treatment with saponin (that induces plasma membrane permeability and necrotic death) led to their PI labeling (Figure $2 e, f)$. Transmission electron microscopy analysis confirmed that staurosporine induced a time-dependent cell shrinkage, the filiform flagellated promastigotes becoming round with an increase in vacuoles and lipid bodies (Figure 3a). Staurosporine also caused nuclear damage. Nuclei from control promastigotes displayed a prominent central or slightly excentrical nucleolus, while chromatin was usually distributed peripherally beneath the nuclear membrane (Figure $3 b, t=0$ ). Staurosporine induced (i) convolution of the nuclear outline with a chromatin condensation to the protruding nuclear lobes and a pronounced indentation and breakdown of the nuclear membrane (Figure $3 \mathrm{~b}, t=12 \mathrm{~h}$ ), and (ii) nuclear fragmentation with scattered clusters of condensed chromatin (Figure $3 b, t=24 \mathrm{~h}$ ). There is still a debate about the morphological changes of mitochondria during apoptosis in mammalian cells. ${ }^{9}$ In control L. major promastigotes, the cristae of the giant mitochondrion were visible (Figure $3 c, t=0$ ) and during cell death, a dilatation of the mitochondrial matrix occurred, leading to the destruction of the internal structure of the mitochondrion (Figure $3 c t=12$ and $24 \mathrm{~h}$ ). Finally, previous studies have reported that PCD is associated with DNA fragmentation in multiples of oligonucleosomal-like fragments in the kinetoplastids $T$. cruzi, ${ }^{25} T$. brucei rhodesiense $e^{26}$ and L. amazonensis. ${ }^{27}$ However, while staurosporine induced DNA degradation in $L$. major, we did not observe a typical oligonucleosomal fragmentation (Figure $4 \mathrm{~b}$, lane 2). In addition to staurosporine, other drugs or conditions that trigger apoptosis in mammalian cells, such as actinomycin $\mathrm{D}$, geneticine, UV treatment, heat shock and serum deprival, also induced in L. major a death process with the same apoptosis-like features (data not shown). In contrast, etoposide, a drug that triggers apoptosis in most mammalian cell types, did not cause L. major cell death (data not shown). Together, our findings indicated that $L$. major promastigotes express a cell death machinery able to execute several features of apoptosis that have been described in mammalian cells.

\section{A broad caspase inhibitor and a broad calpain/ cysteine proteinase inhibitor prevent DNA degradation but not cell death in $L$. major}

Caspases are major effectors of the apoptotic phenotype of PCD in the mammalian cells, , $, 6,7,33$ although other cysteine proteinases, such as calpain, have also been reported to be involved. ${ }^{37}$ While dispensable for the execution of cell death in several instances, ${ }^{11-16}$ caspase activity is crucial for the induction of the typical features of nuclear apoptosis. ${ }^{4,6,7,33}$ To investigate whether cysteine proteinases may also be involved in the induction of the apoptosis-like phenotype caused by staurosporine in L. major, we used the broad mammalian caspase inhibitor BAF and the broad calpain/cysteine proteinase inhibitor E64. Flow cytometry analysis (Figure 4a) and standard DNA agarose gel electrophoresis (Figure $4 \mathrm{~b}$ ) of promastigotes incubated for $24 \mathrm{~h}$ with staurosporine in the absence or presence of either BAF or E64 showed that each inhibitor led to a significant reduction in DNA degradation. We did not increase the protection against $L$. major DNA degradation by adding both E64 and BAF (data not shown), suggesting that the two inhibitors act on the same target(s) or on targets that are downstream to each other. Inhibitors that target other proteinase, such as the serine-proteinase inhibitor tosyl-lysylchloromethane, the cathepsin inhibitor z-FA-fmk or the proteasome inhibitor lactacystin did not prevent the DNA degradation induced by staurosporine in $L$. major (data not shown). Finally, while the cysteine proteinase inhibitors reduced DNA degradation, they neither prevented the cytoplasmic features of apoptosis induced by staurosporine, such as cell shrinkage, $\Delta \Psi \mathrm{m}$ disruption and PS exposure, nor protected L. major against cell death (data not shown). Interestingly, this is similar to our observation concerning the effect of BAF on staurosporine-induced apoptosis in human HEK293T and Hela cells (data not shown).

\section{The cysteine proteinase(s) involved in nuclear apoptosis-like features during $L$. major cell death also induce chromatin condensation and fragmentation and DNA degradation in isolated human nuclei}

To further investigate the nuclear targets of cysteine proteinase(s) involved in DNA degradation during $L$. major cell death, we used a cell free system assay. ${ }^{38}$ Isolated human nuclei (purified from CEM cells) were used as substrates for cytoplasmic extracts from untreated or staurosporine-treated L. major promastigotes. Cytoplasmic extracts from staurosporine-treated promastigotes induced shrinkage of human nuclei, with chromatin condensation and fragmentation, as shown by fluorescence microscopy using Hoechst staining, as well as DNA degradation (hypodiploidy), as shown by flow cytometry analysis (Figure 5a). These nuclear changes were similar to those induced by cytoplasmic extracts from apoptotic human Jurkat cells that had been incubated with an agonistic anti-CD95 antibody (Figure 5c). In contrast, cytoplasmic extracts from control promastigotes (Figure 5a), as those from control Jurkat cells (Figure $5 \mathrm{c}$ ), caused neither nuclear chromatic change nor DNA degradation. As a control for a potential effect of the residual amounts of staurosporine that may have remained (despite the extensive promastigote washings) in the promastigote cytoplasmic extracts, we incubated the human nuclei with various concentrations of staurosporine alone $(0.04 ; 0.4 ; 4 ; 40$ and $400 \mathrm{mM}$ ), the latter concentration corresponding to the total amount of staurosporine that had been initially added to the entire culture of promastigotes whose cytoplasmic extracts were subsequently incubated with the human nuclei. No nuclear chromatin condensation or fragmentation was induced, and flow cytometry analysis of DNA using PI staining showed no induction of DNA degradation (hypodiploidy) induced by these concentrations of staurosporine alone (between $14.6 \%$ and $16.9 \%$ ) when compared to incubation in medium alone (18.3\%) (data not shown). When cytoplasmic extracts from staurosporine-treated $L$. major promastigotes were incubated with isolated human nuclei in the presence of either BAF or E64 (100 $\mu \mathrm{M})$, a significant inhibition of nuclear damage was observed (Figure 5a). In contrast, only BAF, but not E64, inhibited the induction of nuclear apoptosis by cytoplasmic extracts from apoptotic Jurkat cells (Figure 5c), confirming that caspases are the crucial effector proteinases 
of nuclear apoptosis in human cells. ${ }^{4,6,33}$ Finally, standard DNA agarose gel electrophoresis indicated that cytoplasmic extracts from staurosporine-treated promastigotes induced in isolated human nuclei a DNA degradation pattern (Figure 5b) resembling that occurring in the nuclei of the staurosporinetreated promastigotes (Figure 4b), and differing from the typical oligonucleosomal DNA fragmentation induced in the same isolated human nuclei by the cytoplasmic extracts from apoptotic human Jurkat cells (Figure $5 d$ ). Both BAF and E64 inhibited DNA degradation induced by cytoplasmic extracts from promastigotes treated with staurosporine (Figure 5b), while only BAF, but not E64, prevented DNA fragmentation induced by cytoplasmic extracts from CD95 antibody treated Jurkat cells (Figure 5d).
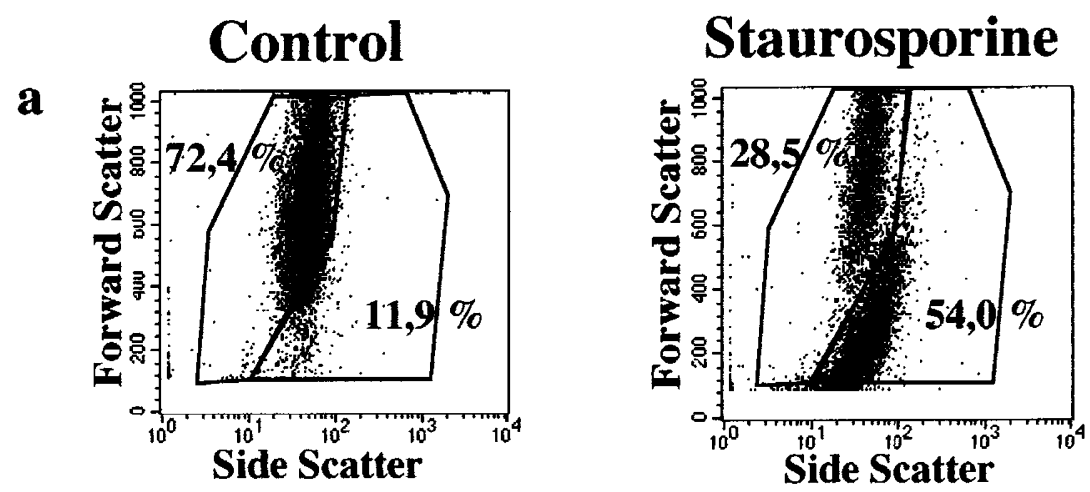

$\mathbf{b}$

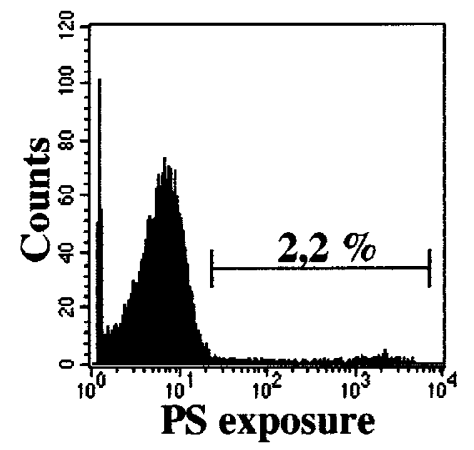

c

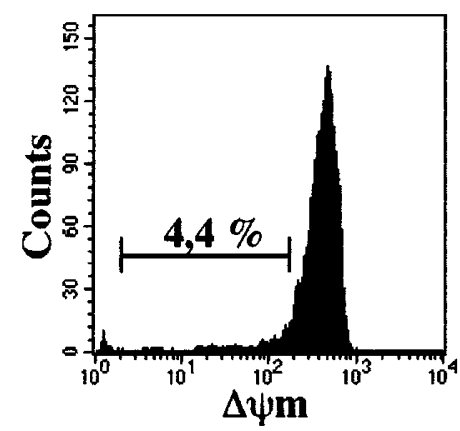

d

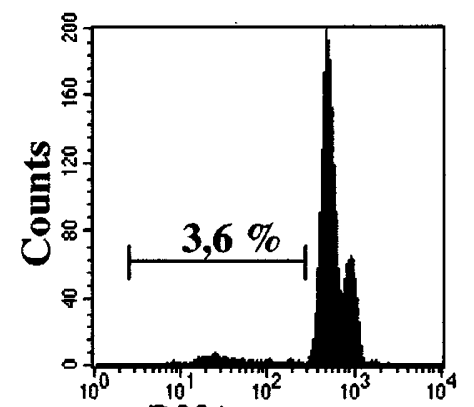

DNA content
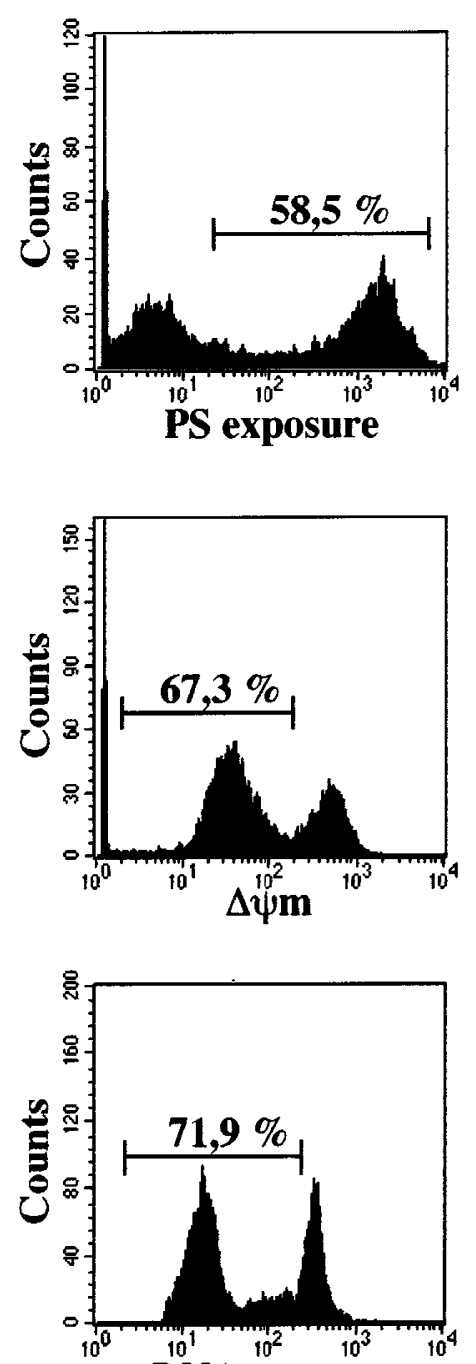

DNA content 
The cysteine proteinase(s) involved in L. major cell death induce the cleavage of human nuclear PARP and ICAD

We investigated whether some of the nuclear proteins cleaved by activated effector caspases during mammalian $\mathrm{PCD}^{4,6,33}$ may also be cleaved by cytoplasmic extracts from dying L. major in a cell free system. We chose two well characterized nuclear substrates of human effector caspases: PARP, ${ }^{39}$ involved in DNA repair, and ICAD, the inhibitor of the CAD endonuclease, responsible for oligonucleosomal DNA fragmentation. ${ }^{33,40}$ We incubated isolated human nuclei with cytoplasmic extracts from control or staurosporine-treated $L$. major promastigotes, and subjected them to Western blotting using specific antibodies to human PARP and ICAD. Cytoplasmic extracts from staurosporine-treated promasti- gotes induced the cleavage of PARP (115 kD), and of the two isoforms of ICAD (45 and $40 \mathrm{kD}),{ }^{41}$ and both PARP and ICAD cleavage were inhibited by BAF and E64 (Figure 6a). However, when compared to the cleavage induced by apoptotic Jurkat cytoplasmic extracts, PARP was cleaved into a $40 \mathrm{kD}$ fragment, and not into the typical $85 \mathrm{kD}$ fragments processed by caspases ${ }^{39}$ and the $45 \mathrm{kD}$ ICAD isoform was less extensively processed and showed a slight molecular weight loss (Figure 6a). Together, these data suggested that cytoplasmic extracts from apoptotic $L$. major promastigotes contain one or more BAF/E64-inhibitable cysteine proteinase(s) that can induce the cleavage of at least two human caspase nuclear substrates, while processing these substrates in a different manner than human caspases. To assess whether the cysteine proteinase(s) involved in $L$. major cell death were directly responsible for the

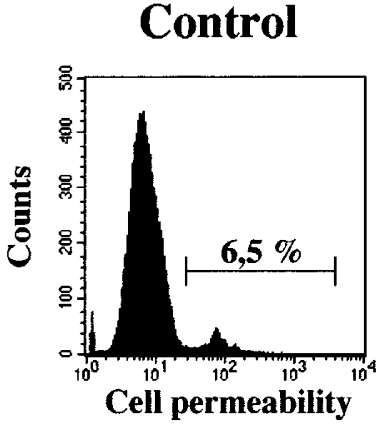

Staurosporine

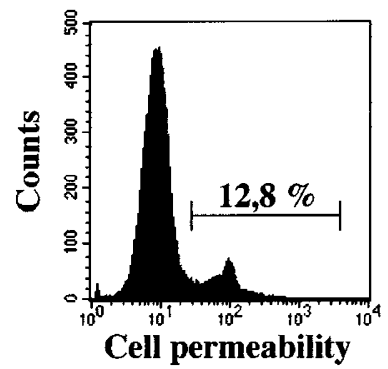

Saponine

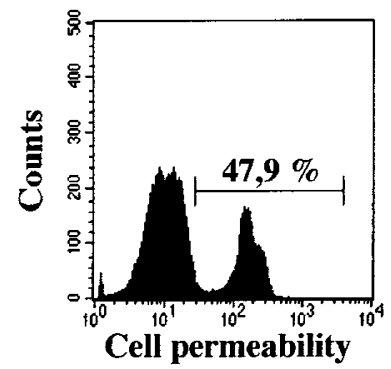

f

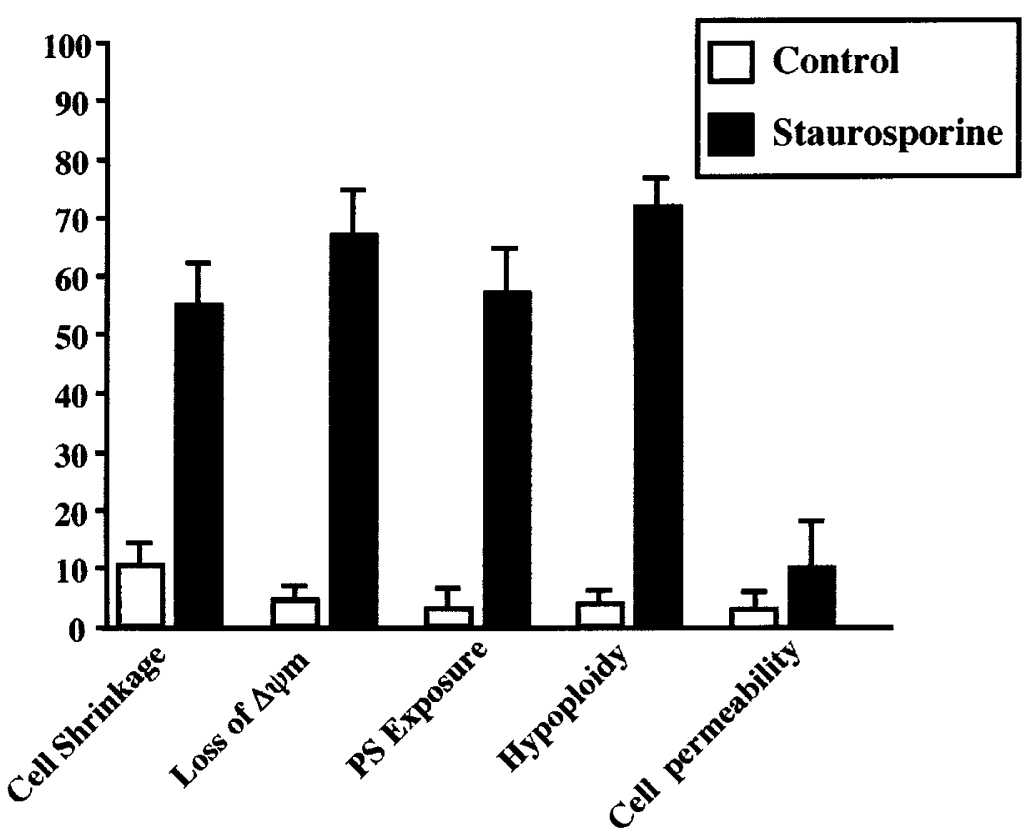

Figure 2 Flow cytometry analysis of the apoptotic features of $L$. major cell death. L. major were incubated in the absence (Control) or presence (staurosporine) of staurosporine $(4 \mu \mathrm{M})$ for $24 \mathrm{~h}$ and (a) light scattering properties, (b) phosphatidyl serine exposure (PS), (c) mitochondrial membrane potential ( $\Delta \Psi \mathrm{m})$, (d) DNA degradation and (e) plasma cell membrane integrity were analyzed by flow cytometry, as indicated in Materials and Methods. Plasma membrane permeabilization (e) of $L$. major by saponin $(0.5 \%)$ was used to induce necrosis. Histograms in (f) are representative of three independent experiments 
cleavage of PARP, we incubated human recombinant PARP with cytoplasmic extract from $L$. major promastigotes that had been incubated for $24 \mathrm{~h}$ in the absence or presence of staurosporine. The recombinant PARP, produced in E. coli was present in the $115 \mathrm{kD}$ form and in a $85 \mathrm{kD}$ form (Figure $6 b)$. Cytoplasmic extracts from dying $L$. major promastigotes also induced the cleavage of recombinant PARP into a $40 \mathrm{kD}$ fragment, and the cleavage was prevented by treatment with either BAF or E64 (Figure 6b).

\section{L. major cell death is associated with the release of cytochrome $c$ from the mitochondrion}

In mammalian cells, PCD involves mitochondrial outermembrane permeabilization, leading to the intracytosolic release of pro-apoptotic proteins, including cytochrome $c^{3,8-10}$ Cytochrome $c$ is highly conserved across evolution, and searches in $L$. major DNA databases indicated that an homolog is present in this organism (data not shown). Antibodies specific for mammalian cytochrome $c$ did not cross-react with any $L$. major protein, but a rabbit polyclonal antibody raised against Saccharomyces cerevisiae cytochrome $c^{42}$ recognized a protein with the expected molecular weight $(14 \mathrm{kD})$ in total cell extracts of promastigotes and in extracts of purified mitochondria (data not shown). Cell fractionation showed that, while a small amount of cytochrome $c$ was present in the cytoplasmic fraction of control promastigotes, cytochrome $c$ was abundant in the cytoplasmic fraction of staurosporine treated promastigotes (Figure 7a). Because the mitochondrion has a very important size in the cell, some mitochondria were probably broken, accounting for both the small amount of cytochrome $c$ present in the cytosolic extract fraction of control promastigotes, and for the small amount of Hsp60 (a protein of the mitochondrial matrix) present in the cytosolic extract fraction of both control and dying promastigotes. The mitochondrial release of cytochrome $c$ induced by staurosporine was confirmed by immunofluorescence microscopy analysis using the same antibody to yeast cytochrome $c$ (Figure $7 b$ ). Cytochrome $c$ (in red) was co-localized with the mitochondrion stained in green with MitoTracker in control promastigotes, while being a

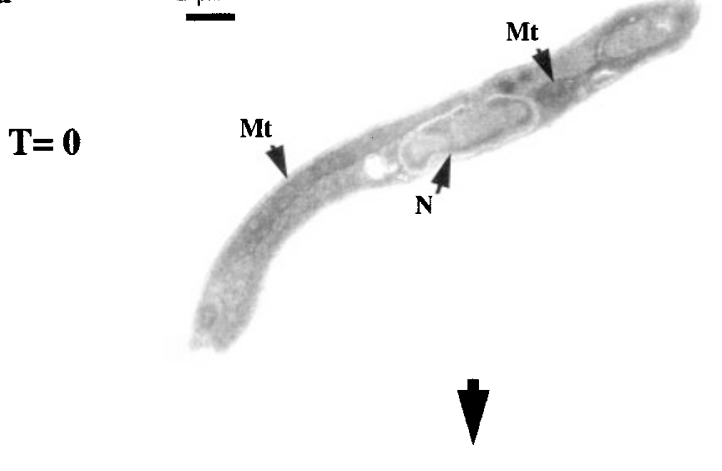

$\mathrm{T}=12 \mathrm{~h}$

$\mathrm{T}=\mathbf{2 4 h}$

\section{$2 \mu \mathbf{M}$}

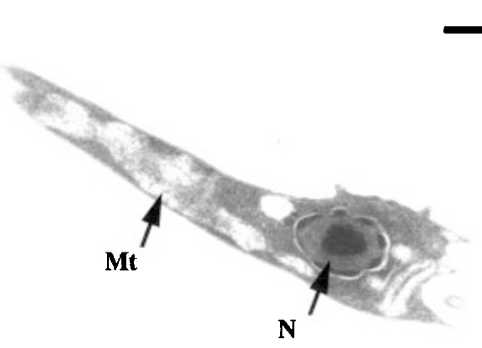

$\checkmark$

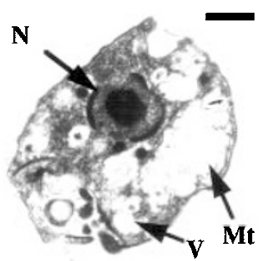

b

$\mathbf{T}=\mathbf{0}$

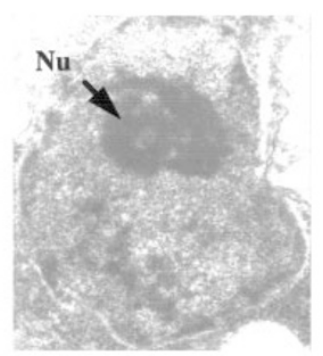

$T=12 h$
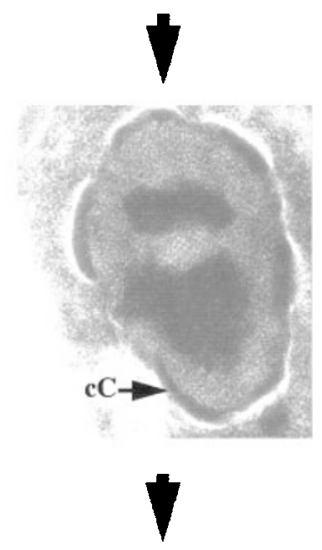

$\mathbf{T}=\mathbf{2 4 h}$

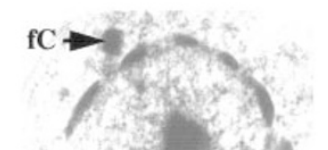

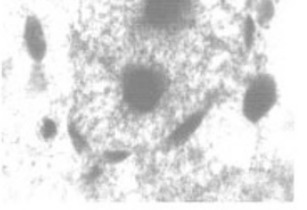


diffuse in the cytosol of apoptotic promastigotes, indicating that it was released from the mitochondrion. AIF is another mitochondrial protein, conserved across evolution, ${ }^{43}$ that is released into the cytosol during mammalian cell PCD, and participates to the induction of caspase-independent cell death pathways. We found an AIF homolog in the L. major DNA database (data not shown). We were intrigued by our observation that when cytoplasmic extracts of dying promastigotes that had been treated with BAF or E64 were incubated with isolated human nuclei, chromatin fragmentation and DNA degradation were prevented, as previously mentioned (Figure 5a), but the nuclei were showing small changes, i.e. peripheral nuclear chromatin condensation, that have been defined as stage I of nuclear apoptosis in human cells and reported to be induced by AIF. ${ }^{43}$ We could however not investigate whether an AIF homolog may also be released by the mitochondrion during $L$. major apoptosis, because neither an antibody specific for mammalian AIF $^{43}$ nor an antibody that we raised against a Dictyostelium discoideum AIF homolog ${ }^{44}$ allowed the detection in $L$. major of a protein with a molecular weight similar to that expected for an AIF homolog (around $55 \mathrm{kD}$ ).

\section{Bax induces the release of cytochrome $c$ and of a cysteine proteinase activity from $L$. major purified mitochondria}

In mammalian cells, mitochondrial permeabilization induced by pro-apoptotic stimuli results from the binding to the mitochondrial outer membrane of members of the Bax/Bak protein family. ${ }^{3,8-10}$ Human recombinant Bax binds in vitro to the outer membrane of isolated human and murine mitochondria through its carboxy terminal transmembrane domain, and induces mitochondrial release of cytochrome $c .^{3,8-10}$ The evolutionary conservation of Bax target(s) on the mitochondrial outer membrane is suggested by reports indicating that Bax expression in yeasts induces mitochondrial dysregulation and yeast cell death. ${ }^{45-47}$ Using recombinant human Bax protein and purified L. major promastigotes mitochondria, we explored whether Bax may induce mitochondrion permeabilization. The full length recombinant Bax (400 nM) induced a rapid $(15 \mathrm{~min}$ ) release of cytochrome $c$ in the supernatant (Figure 8a). In contrast, mitochondria incubated in the absence of Bax did not release cytochrome $c$ during $1 \mathrm{~h}$. Supernatants of Bax-treated L. major mitochondria, when

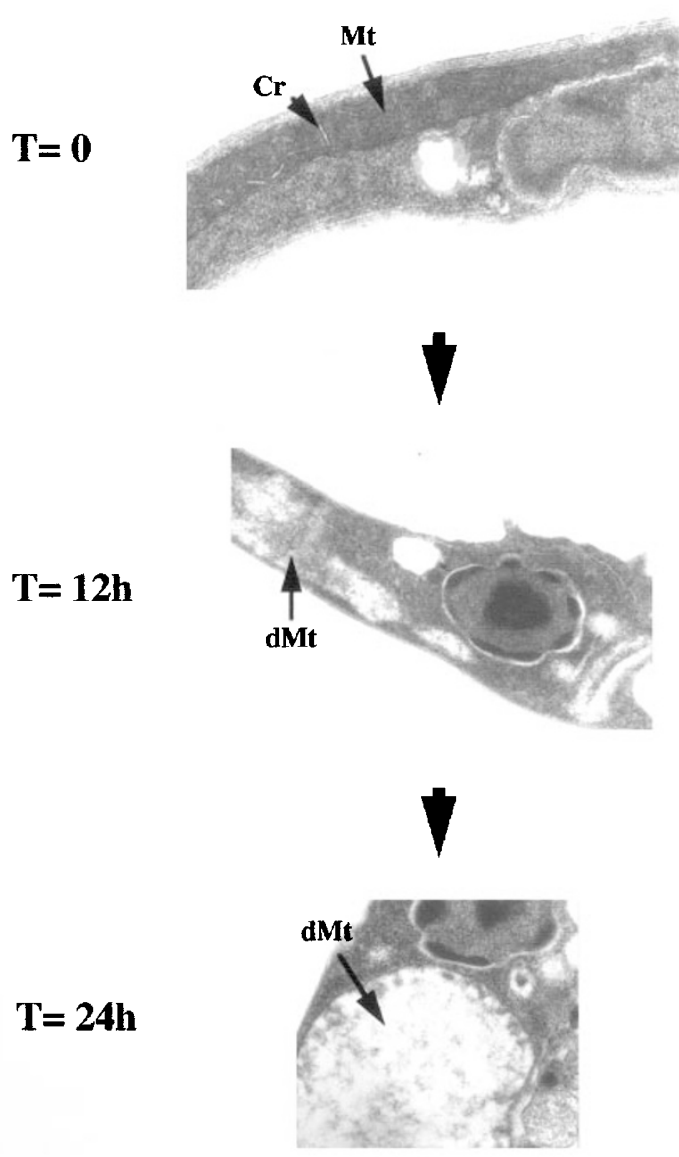

Figure 3 Electron microscopy analysis of the apoptotic features of $L$. major cell death. $L$. major were incubated in the absence $(t=0)$ or presence $(t=12 \mathrm{~h}$ and $t=24 \mathrm{~h}$ ) of staurosporine $(4 \mu \mathrm{M})$ and cell morphology was monitored by electron microscopy. (a) Morphology of the whole cell during staurosporine mediated cell death. Magnification $13000 \times$. Mt=Mitochondrion; N=Nucleus; V=Vacuoles. Bar=2 $\mu \mathrm{M}$. (b) Nuclear morphology during staurosporine mediated cell death Magnification 38,500 $\times$. Nu=Nucleolus, $\mathrm{cC}=$ condensed Chromatin, $\mathrm{fC}=$ fragmented Chromatin. (c) Mitochondrion morphology during staurosporine-mediated cell death. Magnification $28000 \times$. Cr=Cristae; Mt=Matrix; dMt=dilated Matrix 
incubated with isolated human nuclei, induced chromatin condensation and fragmentation and DNA degradation (hypodiploidy) (Figure 8b), that were similar to those induced by cytoplasmic extracts of staurosporine treated $L$. major promastigotes (Figure 5a,b), and were also prevented by the addition of the cysteine proteinase inhibitors BAF or E64 (Figure 8b). In contrast, supernatants of $L$. major mitochondria incubated in the absence of Bax induced neither chromatin damage nor DNA degradation in isolated human nuclei (Figure $8 \mathrm{~b}$ ). These findings indicated (i) that the capacity of $\mathbf{a}$

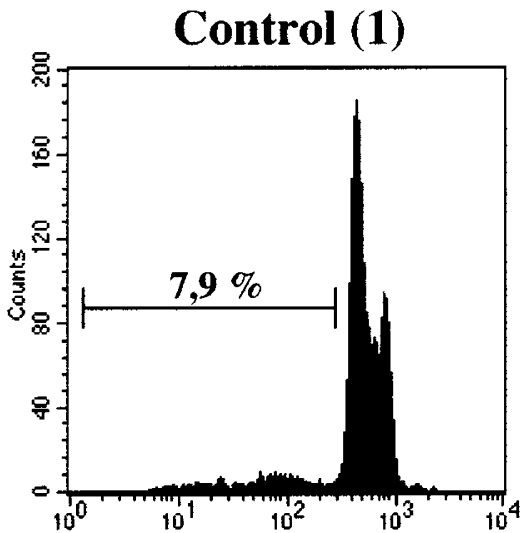

DNA content

Staurosporine

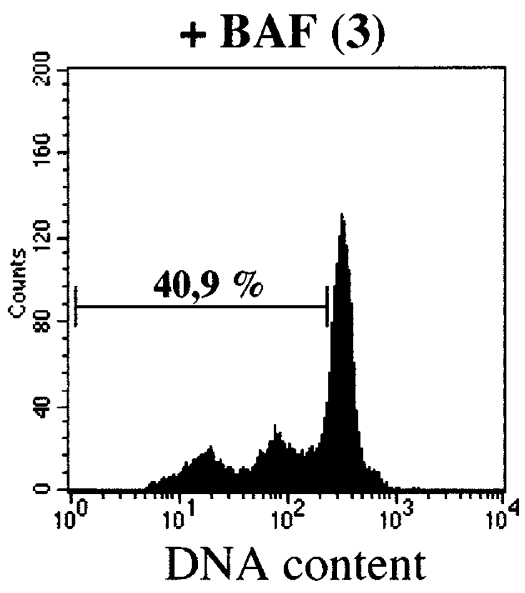

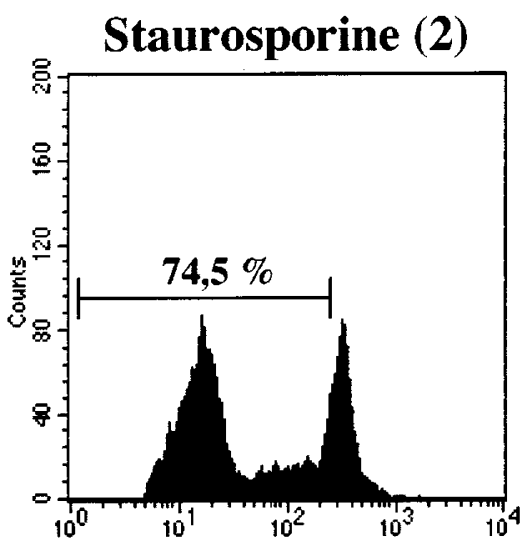

DNA content

Staurosporine

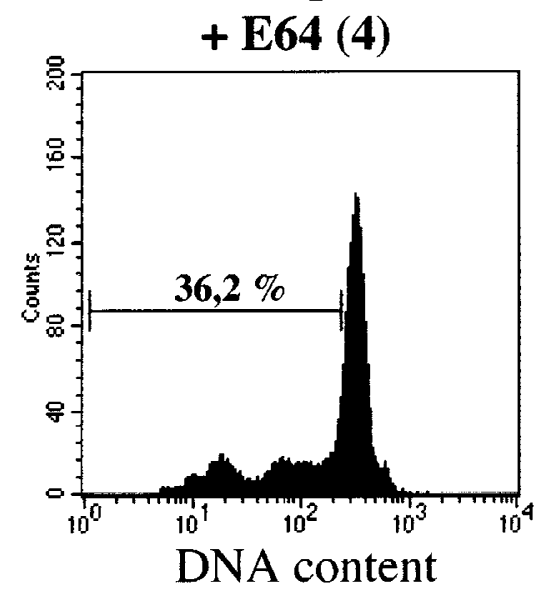

b

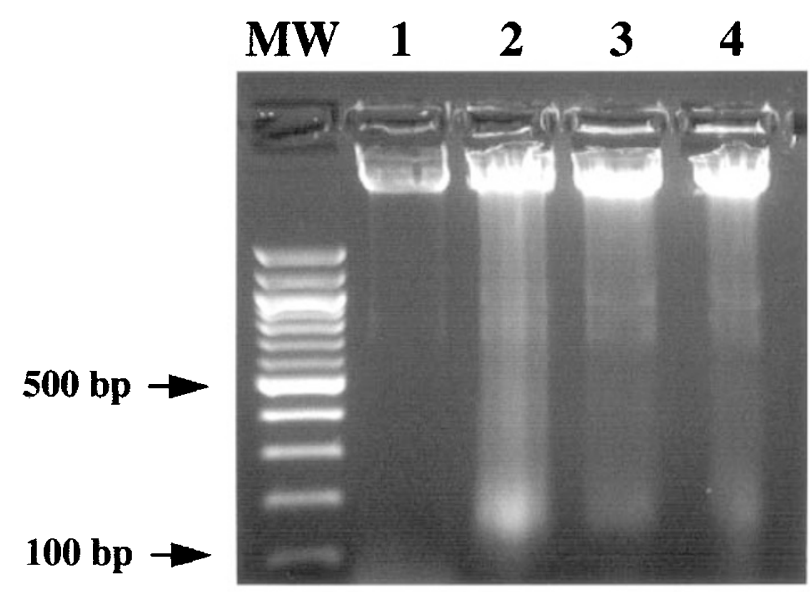

Figure 4 Cysteine proteinase inhibitors prevent the induction of nuclear apoptosis-like features in L. major. L. major were incubated for $24 \mathrm{~h}$ in medium alone (1) or with staurosporine $(4 \mu \mathrm{M})$ in the absence (2) or presence of BAF (3) or E64 (4), added 3 times (at $100 \mu \mathrm{M}$ each), and the L. major DNA degradation (hypodiploidy) was assessed by flow cytometry (a) and standard agarose gel electrophoresis (b). Per cent in (a) indicate percentages of hypodiploid cells. The data shown are representative of three independent experiments 
human Bax to induce the release of pro-apoptotic factors from mitochondria is conserved across major phylogenic divergence, and (ii) that the L. major mitochondrion contain and release, together with cytochrome $c$, part at least of the BAF and E64 inhibitable cysteine proteinases that we identified in the cytosol of apoptotic promastigotes, and that appear responsible for the induction of the nuclear apoptosis-like features. Finally, we investigated the effect on the L. major mitochondrion of human recombinant Bax protein deleted in its transmembrane domain ( $\triangle \mathrm{TM} B \mathrm{Bax}$ ), required for $\mathrm{Bax}$ insertion into the mitochondria outermembrane. In isolated mammalian mitochondria, $\triangle \mathrm{TM}$ Bax has been reported to induce low levels of cytochrome $c$ release, ${ }^{48}$ presumably through its capacity to oligomerize with members of the proapoptotic $\mathrm{Bcl}-2$ protein family already present, in a monomeric form, on the mitochondria outermembrane. As shown in Figure $8 \mathrm{a}$, incubation for $15 \mathrm{~min}$ of isolated $L$. major mitochondria with $\Delta \mathrm{TM}$ Bax $(400 \mathrm{nM})$ induced a small level of cytochrome $c$ release, that was greatly increased after $1 \mathrm{~h}$ incubation, although still at a lower level than that induced by full length Bax. The absence of Hsp60 in the mitochondria supernatant indicated the absence of mitochondria rupture and spilling in the supernatant (Figure 8a). Thus, Bax was able to induce, to some extent, $L$. major mitochondrion permeabilization in the absence of its transmembrane insertion domain. This suggests the possibility that functional homologs of the pro-apoptotic Bcl-2 family, able to interact with human Bax, are expressed in L. major and present on the mitochondrion membrane.

\section{Discussion}

Here we report that a cell death machinery able to induce several nuclear and cytoplasmic features of apoptosis is present and operational in one of the most ancestral unicellular eukaryote, the kinetoplastid protozoan parasite Leishmania major, whose phylogenic divergence predates by several hundred million years the emergence of the eukaryote terminal crown that includes animals, plants and fungi. ${ }^{31,32}$

Our findings indicate that this apoptotic cell death process is triggered in L. major, as in mammalian cells, by the protein kinase inhibitor staurosporine. Our findings also provide the first evidence, to our knowledge that the cytoplasmic effectors of nuclear apoptosis-like features in a unicellular eukaryote have the capacity to induce similar features in isolated human nuclei, and strongly suggest that these effectors are cysteine proteinases.

Treatment of $L$. major with two cysteine proteinase inhibitors, either the broad caspase inhibitor BAF, or the calpain/cysteine proteinase inhibitor E64 prevented the induction of the nuclear features of apoptosis, but had no preventive effect on cell death, suggesting that cysteine proteinase activity in $L$. major, as effector caspase activity in mammalian cells, ${ }^{11-16}$ is important for the execution of nuclear apoptosis but dispensable for the execution of cell death. The BAF/E64 inhibitable cysteine proteinase activity present in the cytoplasmic extracts of dying L. major also induced apoptosis-like features in isolated human nuclei, and cleaved two well characterized human nuclear substrates of effector caspase, ${ }^{4,6,33,39}$ PARP, involved in
DNA repair, and ICAD, the inhibitor of the CAD endonuclease responsible for the internucleosomal cleavage of DNA. The pattern of DNA degradation in L. major differed however from the typical internucleosomal DNA fragmentation that is induced by CAD. ${ }^{33}$ While in $L$. major nuclei this pattern could be due to differences in histone/DNA organization or to a lack of CAD homolog, the fact that cytoplasmic extracts from dying $L$. major induced the same type of DNA degradation in isolated human nuclei indicated that this pattern was due to the activity of the BAF/E64 inhibitable $L$. major cysteine proteinases, and not to particular features of the $L$. major nucleus. Thus, despite processing ICAD in the human nuclei, the $L$. major cysteine proteinases failed to induce the typical CAD-mediated internucleosomal DNA cleavage. One possible explanation, that remains to be explored, is that among the BAF/E64 inhibitable $L$. major cysteine proteinases, some may also induce histone degradation, leading to a mixture of both inter- and intranucleosomal DNA cleavage.

It is unlikely that these $L$. major cysteine proteinases belong to the caspase family. Firstly, no caspase homolog has been yet identified in any unicellular eukaryotes. ${ }^{49}$ While genes encoding metacaspases, belonging to an ancestral metacaspase/paracaspase/caspase superfamily, have been identified in plants, fungi and several unicellular eukaryotes, including protozoans, ${ }^{49}$ nothing is known about their potential involvement in cell death. Secondly, the BAF/ E64 inhibitable L. major cysteine proteinases processed human nuclear PARP, as well as recombinant PARP, into a $40 \mathrm{kD}$ fragment, and not into the $85 \mathrm{kD}$ fragment that is processed by human effector caspases. ${ }^{39}$ Interestingly, it has been recently reported that a human cysteine proteinase, calpain, whose involvement in apoptosis has been suggested, ${ }^{37}$ processes PARP into a $40 \mathrm{kD}$ fragment, and that this calpain activity is prevented by a broad caspase inhibitor. ${ }^{50}$ We identified a calpain-like sequence in the kinetoplastid database (not shown) and it is therefore possible that the BAF/E64 inhibitable L. major cysteine proteinases are calpain-like proteinases. The kinetoplastid protozoan parasites, including $L$. major, contain several different cysteine proteinases, the most abundant and best characterized being the cathepsin B- and L-like proteinases encoded by the $\mathrm{cp} a, b$ and $c$ cluster gene families, that play an important role in the proliferation and differentiation of these parasites. ${ }^{51}$ Recently, it was reported that selective inhibitors of the cathepsin B- and L-like cysteine proteinases inhibit proliferation and induce death in both the extracellular promastigote and the intracellular amastigote stage of $L$. major. ${ }^{52}$ In contrast, we observed no effect of either BAF or E64 on the proliferation and survival of $L$. major promastigotes. Thus, it is possible that among $L$. major cysteine proteinases, some, related to the cathepsin family, may participate in promastigote differentiation, proliferation and survival, while others, possibly related to the calpain family, may participate in the induction of nuclear apoptosis-like features during promastigote death.

In mammalian cells, most pro-apoptotic stimuli induce the activation of the effector caspase cysteine proteinases through a process of mitochondrial outer membrane permeabilization that involves members of the Bax/Bak 
protein family and results in cytochrome $c$ release..$^{3,8-10}$ The evolutionary conservation of mitochondrial Bax target(s) is suggested by findings indicating that Bax expression in yeast induces mitochondrial dysfunction and cell death (cytochrome $c$ release in such instances remaining, however, controversial). ${ }^{45-47}$ Our finding that human recombinant Bax, when incubated with isolated $L$. major mitochondria, induces release of cytochrome $c$, extends these previous observations by indicating that the capacity of human Bax to induce mitochondria permeabi-

$\mathbf{a}$

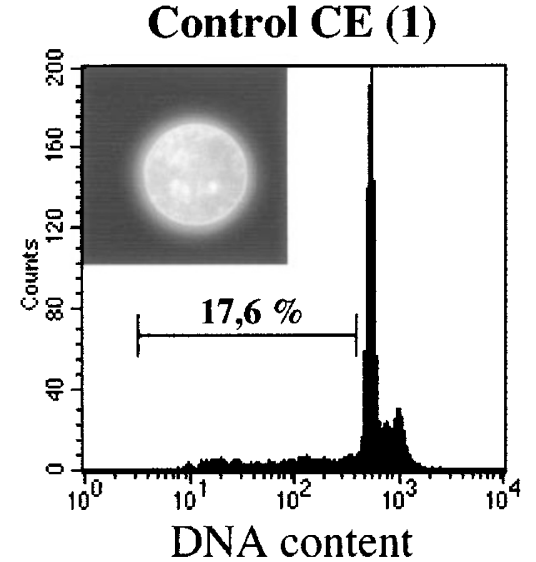

Apoptotic CE + BAF (3)

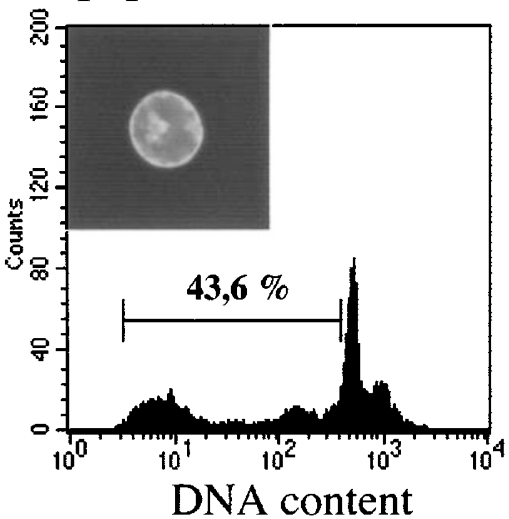

lization is conserved across major phylogenic divergence. Furthermore, our finding that Bax also induces the mitochondrial release of the BAF/E64 inhibitable cysteine proteinases with nuclear pro-apoptotic activity suggests a link between the mitochondrion permeabilization that occurs during $L$. major death and the release and activation of these proteinases, a feature reminiscent of the intramitochondrial localization of procaspase-2, -3 and -9 in mammalian cells, and of their release during apoptosis induction. ${ }^{8-10}$

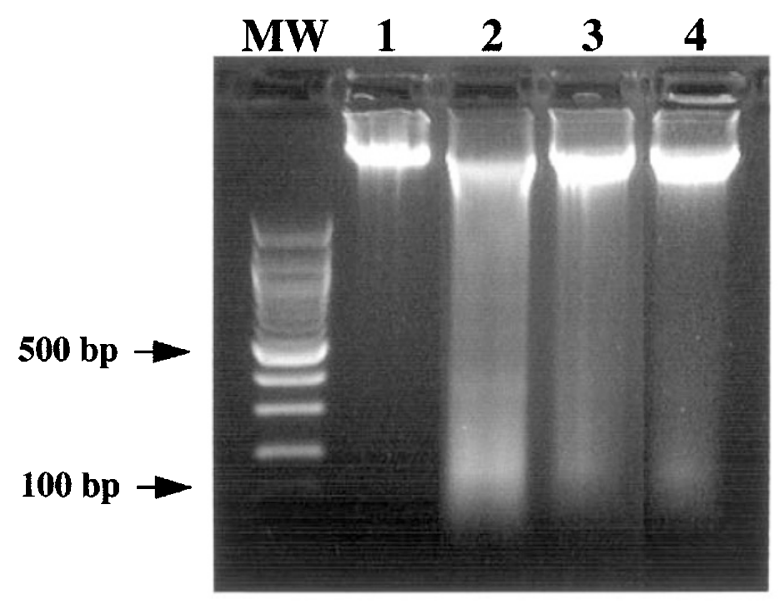


While the capacity of human full length Bax to permeabilize the $L$. major mitochondria may be simply related to evolutionary conservation of mitochondrial targets of Bax, our observation that human recombinant $\Delta \mathrm{TM}$ Bax also induces (although much less efficiently) L. major mitochondrial release of cytochrome $c$ is more surprising. Indeed, $\Delta T M$ c

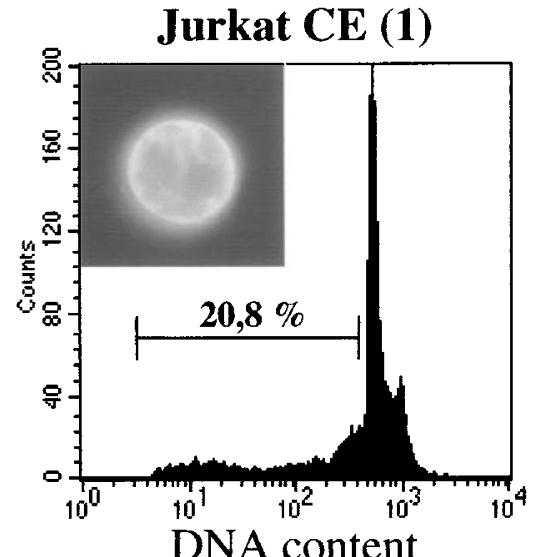

Jurkat/Fas CE + BAF (4)

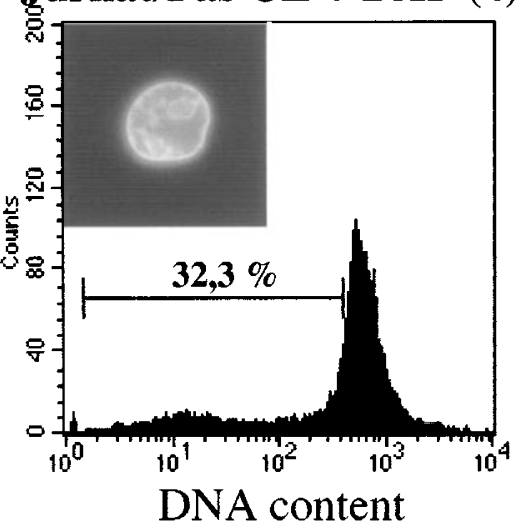

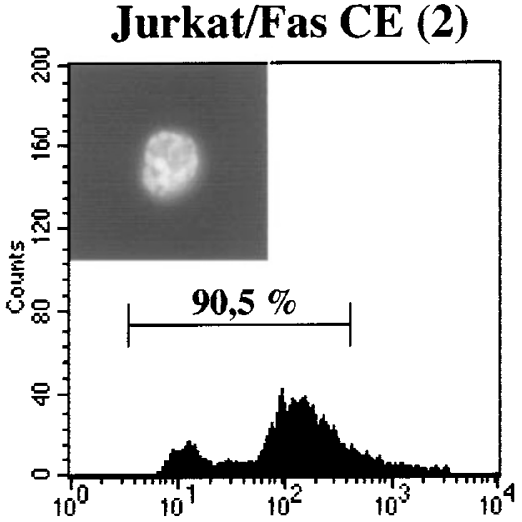

DNA content
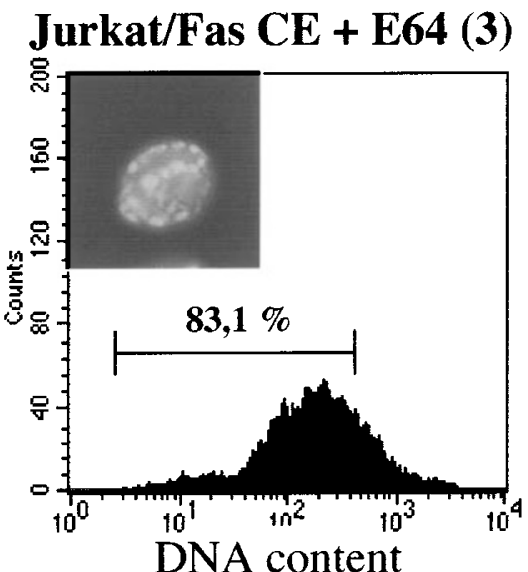

d

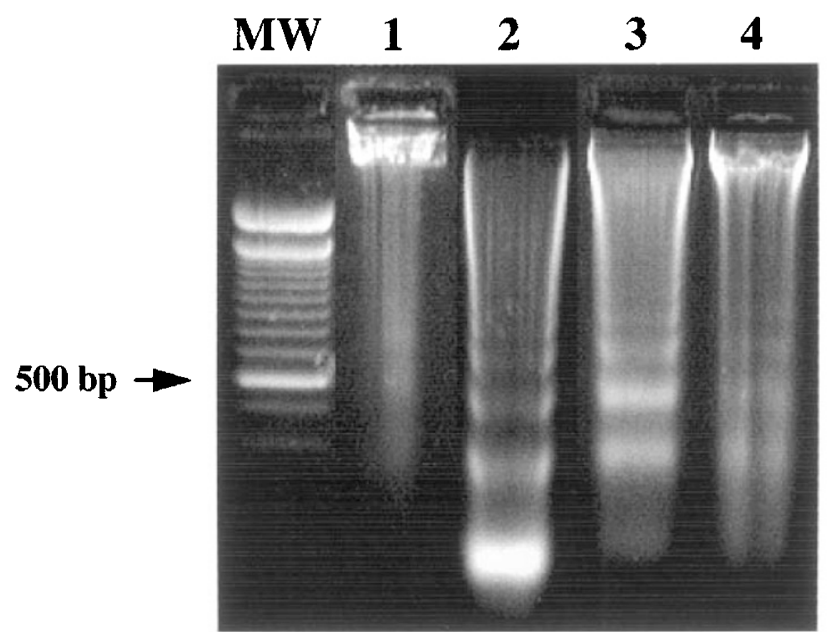

Figure 5 A cysteine proteinase activity in the cytoplasmic extracts from apoptotic L. major induces nuclear apoptosis-like features in isolated human nuclei. Isolated human nuclei were incubated $2 \mathrm{~h}$ with cytoplasmic extracts (CE) from untreated $L$. major promastigotes (1) or from $L$. major promastigotes treated for $24 \mathrm{~h}$ with staurosporine $(4 \mu \mathrm{M})(2)$; BAF $(100 \mu \mathrm{M})(3)$ or $\mathrm{E} 64(100 \mu \mathrm{M})(4)$ were added to the cytoplasmic extracts. Nuclear DNA degradation (hypodiploidy) was assessed by flow cytometry (a) or by standard agarose gel electrophoresis (b). As a control, isolated human nuclei were incubated with cytoplasmic extracts from Jurkat cells cultured for $6 \mathrm{~h}$ in the absence (1) or presence of an agonistic anti-CD95 antibody (2); BAF $(100 \mu \mathrm{M})(3)$ or E64 $(100 \mu \mathrm{M})(4)$ were added to the cytoplasmic extracts. Nuclear DNA degradation was assessed by flow cytometry (c) or by standard agarose gel electrophoresis (d). Nuclear morphology in (a) and (c) was observed under UV fluorescence microscopy after Hoechst staining (magnification $1000 \times$ ). Per cent in (a) and (c) indicate percentages of hypodiploid nuclei. The data shown are representative of three independent experiments 
Bax lacks the carboxy terminal hydrophobic transmembrane domain required for insertion into the mitochondrial outermembrane. In isolated mammalian mitochondria, the $\Delta T M$ Bax protein has been shown to induce cytochrome $c$ release (at levels around 10 times lower than full length Bax), and this effect has been attributed to $\triangle \mathrm{TM}$ Bax oligomerization with the Bak pro-apoptotic protein that is constitutively anchored to the mitochondrial outermembrane, and requires (as full length Bax) oligomerization to induce mitochondrial outermembrane permeabilization. ${ }^{48}$ Accordingly, mammalian cells lacking both Bax and Bak are resistant to cell death induction by ' $\mathrm{BH} 3$ domain-only' proteins that lack the transmembrane insertion domain. ${ }^{53}$ Thus, our finding that $\triangle T M B a x$ is able to induce permeabilization of isolated $L$. major mitochondria suggests the interesting possibility that proteins able to functionally interact with human $\triangle T M$ Bax may be present on the $L$. major mitochondrion surface. Since the absence of Bax and Bak is sufficient to render mammalian cells resistant to staurosporine-induced cell death, ${ }^{53}$ it is tempting to speculate that such putative Bax/ Bak functional homologs may participate in $L$. major to staurosporine-induced cell death. However, since no gene

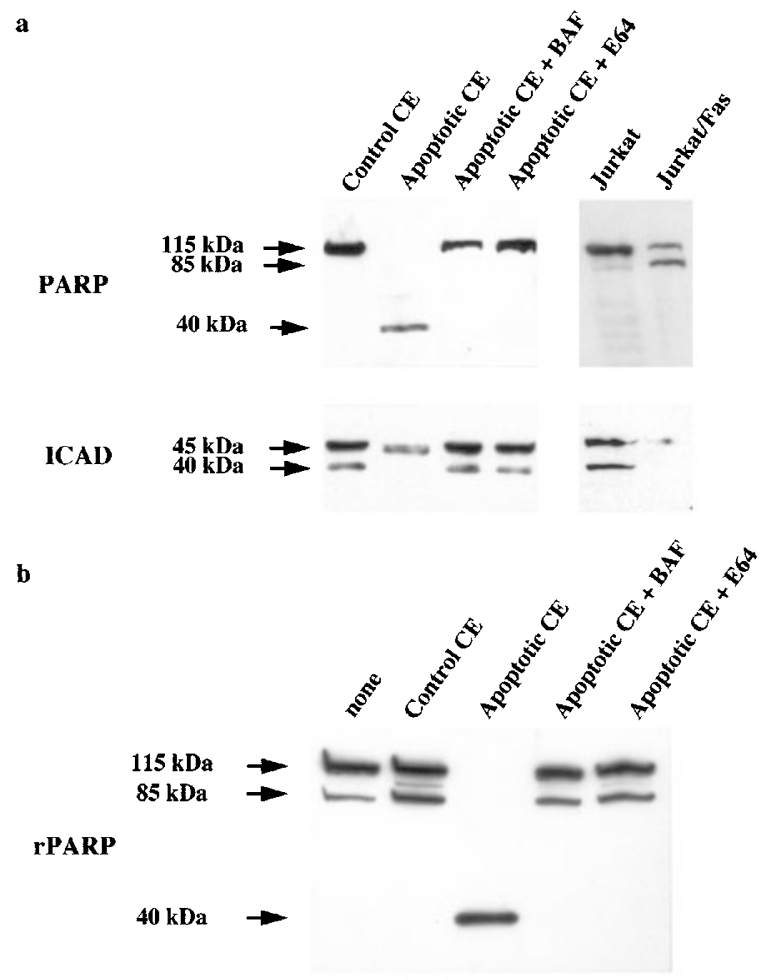

Figure 6 Cytoplasmic extracts from apoptotic $L$. major induce the cleavage of human nuclear PARP and ICAD in a cell free system. (a) Isolated human nuclei were incubated with the same $L$. major cytoplasmic extracts as described in Figure 5. The cleavage of mammalian nuclear PARP and ICAD was then assessed by Western blotting. (b) Recombinant PARP $(500 \mathrm{ng})$ was incubated with the same $L$. major cytoplasmic extracts described in Figure 5 and its cleavage was assessed by Western blotting. The data shown are representative of three independent experiments sequence homology with any domain of the $\mathrm{Bcl}-2 / \mathrm{Bax}$ protein family has yet been identified in unicellular eukaryotes, ${ }^{49}$ the potential nature of such functional homologs remains puzzling, and further investigations are required to assess whether they are indeed present in L. major.

Finally, independently of the molecular nature of the effectors involved, our finding that $L$. major has the capacity to achieve cytoplasmic features of apoptosis, including phosphatidyl serine exposure with maintenance of plasma membrane integrity, may have implications for the pathogenesis of this parasite, that causes severe diseases in humans. Indeed, a series of recent findings suggest that the ingestion of apoptotic mammalian cells by macrophages or dendritic cells induces a downregulation of the macrophage capacity to secrete pro-inflammatory cytokines and of the dendritic cell capacity to activate an immune response to foreign antigens, while ingestion of necrotic, membrane-damaged cells does not have these effects. ${ }^{34,54}$ Ingestion of apoptotic mammalian cells has also been reported to induce in macrophages a change in metabolism that favors the growth, inside the macrophage, of another kinetoplastid parasite, Trypanosoma cruzi. ${ }^{55}$ Therefore, it is possible that the ability of $L$. major to undergo a cell death process with an apoptosis-like phenotype may play a role in favoring both parasite evasion from the host immune response, and parasite growth in the infected macrophages.

In conclusion, our findings indicate that an apoptotic cell death machinery involving cysteine proteinases and the mitochondrion is present in a unicellular eukaryote of very ancient phylogenic divergence. While this apoptotic machinery may therefore be of very ancient origin, it is also possible that its emergence is a more recent consequence of the evolution of kinetoplastids into parasites of both invertebrate and vertebrate hosts, and may have resulted either, as mentioned above, from strong selective pressures exerted on their cell death phenotype, or from horizontal transfers of host genes. Kinetoplastids should provide a valuable model to elucidate to what extent shared ancestry, horizontal gene transfer, or evolutionary convergence may have been instrumental in shaping the evolution of PCD, and to what extent the capacity to undergo apoptotic cell death may have played a role in the capacity of single celled eukaryote parasites to invade their metazoan hosts.

\section{Materials and Methods}

\section{Cells and culture conditions}

L. major (WHO strain WHOM/IR/-/173), kindly provided by Dr. YJF Garin (CHU Saint Louis, Paris), were cultured as promastigotes in M199 medium (Gibco/BRL, Gaithersburg, MD, USA) with 20\% fetal calf serum, L-glutamine $(2 \mathrm{mM}), 100 \mathrm{U} / \mathrm{ml}$ penicillin (Gibco) and $100 \mathrm{mg} / \mathrm{ml}$ streptomycin (Gibco) at a temperature of $27^{\circ} \mathrm{C}$. To induce cell death, $L$. major cells were incubated in presence of staurosporine $(4 \mu \mathrm{M})$ (Sigma, Saint Louis, MI, USA). DNA degradation was inhibited by addition of $100 \mu \mathrm{M}$ of BAF (Calbiochem, San Diego, CA, USA) or E64 (Sigma), 30 min before the addition of staurosporine and 6 and 
a

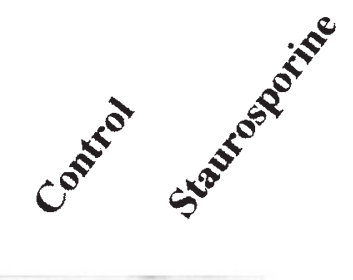

Cyt c

Hsp 60

b

\section{Control}
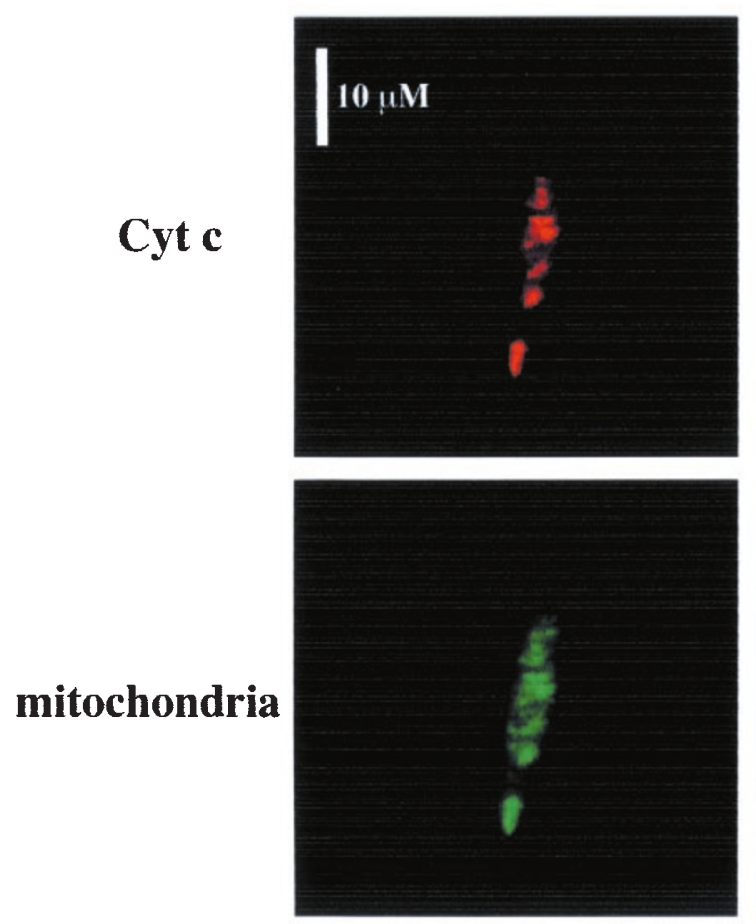

\section{Staurosporine}
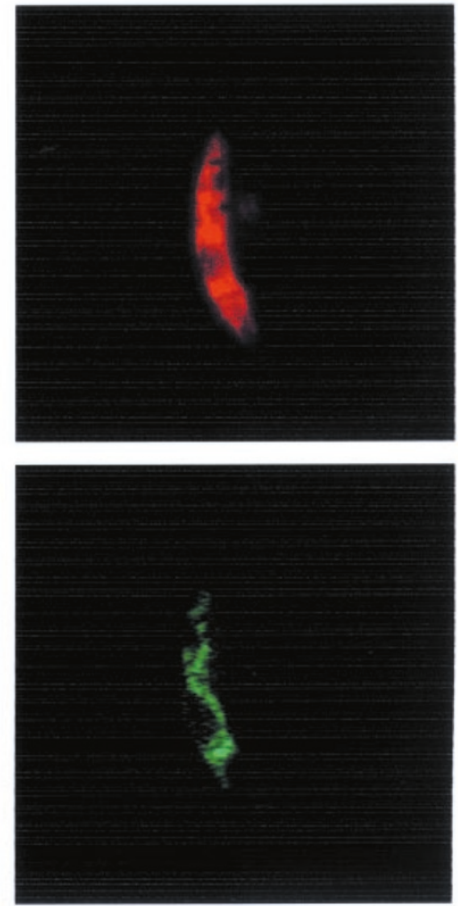

Figure 7 L. major cell death is associated with the release of cytochrome $c$ from the mitochondrion. (a) Cytosolic fractions from untreated (Control) or Staurosporine $(4 \mu \mathrm{M})$-treated $L$. major promastigotes were analyzed for the presence of cytochrome $c$ and Hsp60 by Western blotting. (b) Cytochrome $c$ localization in untreated (Control) or Staurosporine $(4 \mu \mathrm{M})$-treated $L$. major was also studied by immunofluorescence. Magnification $1500 \times$. The data shown are representative of three independent experiments

$12 \mathrm{~h}$ after. Human Jurkat T-cells were cultured at $37^{\circ} \mathrm{C}$ in RPMI 1640 (Gibco) supplemented with $10 \%$ heat-inactivated fetal bovine serum (Summit Biotechnology, Greeley, CO, USA), 2 mM L-glutamine, $1 \mathrm{mM}$ sodium pyruvate (Gibco), and $100 \mathrm{U} / \mathrm{ml}$ penicillin (Gibco) and $100 \mathrm{mg} /$ $\mathrm{ml}$ streptomycin (Gibco). In order to induce apoptosis, Jurkat cells $\left(10^{6} / \mathrm{ml}\right)$ were incubated for $6 \mathrm{~h}$ in the absence or presence of the agonistic CD95 IgM mAb (CH11) $(1 \mu \mathrm{g} / \mathrm{ml})$ (Coulter Corporation, Fullerton, CA, USA).

\section{Flow cytometric analysis}

The mitochondrial transmembrane potential $(\Delta \Psi \mathrm{m})$ was measured by incubating cells with 3,3'-dihexyloxacarbicyanine iodide $-\mathrm{DiOC}_{6}(3)$ (Molecular Probes, Eugenes, OR, USA) at a concentration of $2.5 \mathrm{nM}$. Plasma membrane integrity was assessed by using propidium iodide (Sigma) in the absence of cell permeant. Phosphatidylserine (PS) exposure on the outer plasma membrane was measured by staining cells with $1 \mu \mathrm{g} / \mathrm{ml}$ of annexin V-FITC (Coulter Corporation). Relative 
a

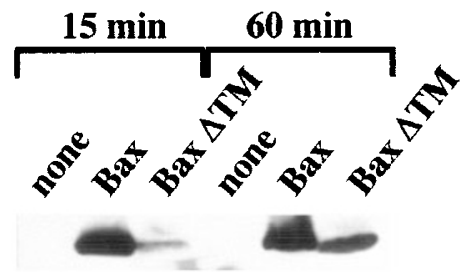

Hsp 60

b

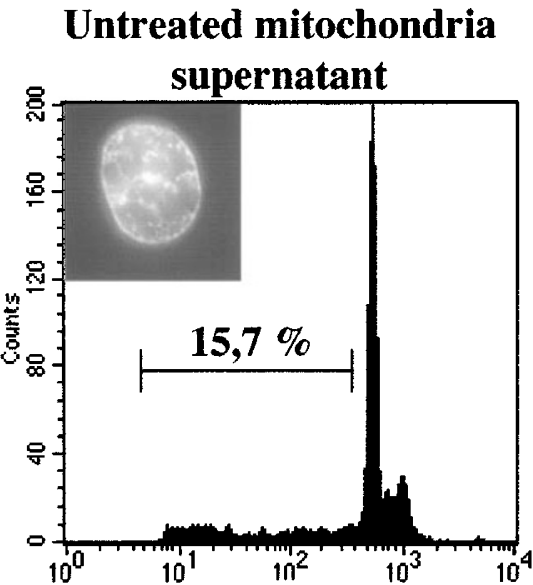

DNA content

Bax treated mitochondria

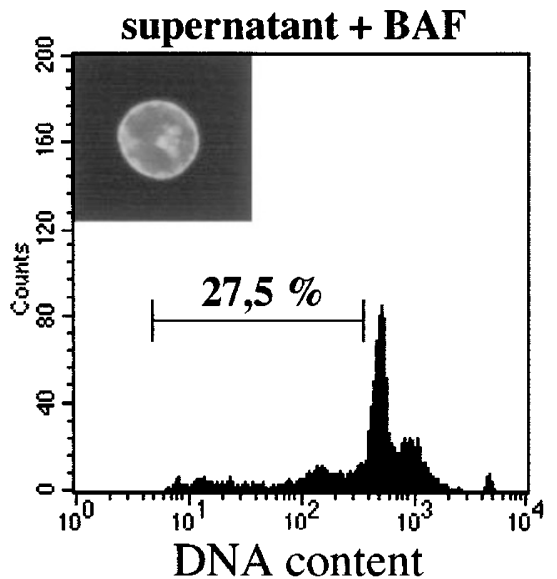

Bax treated mitochondria supernatant

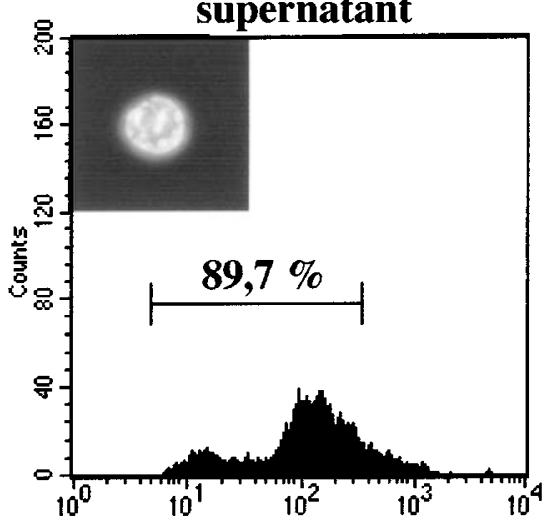

DNA content

Bax treated mitochondria

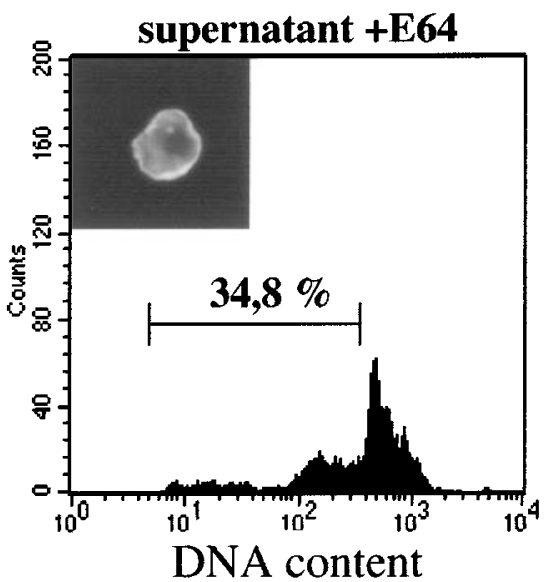

Figure 8 Bax induces the release of cytochrome $c$ and of cysteine proteinase(s) with nuclear pro-apoptotic activity from L. major purified mitochondria. (a) Purified L. major mitochondria were incubated in medium alone (none) or with $400 \mathrm{nM}$ of either full length (Bax) or $\Delta \mathrm{TM}$ (Bax $\Delta T \mathrm{TM}$ ) recombinant human Bax for 15 or $60 \mathrm{~min}$. The presence of cytochrome $c$ in the mitochondrial supernatant was then analyzed by Western blotting. Detection of Hsp60 was used to control for the absence of mitochondrial contamination in the supernatant. (b) Isolated human nuclei were incubated for $4 \mathrm{~h}$ with supernatants of mitochondria that had been preincubated for $1 \mathrm{~h}$ in medium alone (1) or with human full length recombinant Bax (400 nM) (2); BAF (100 $\mu \mathrm{M})(3)$ or $\mathrm{E} 64$ $(100 \mu \mathrm{M})(4)$ were added to the supernatants of the mitochondria that had been preincubated for $1 \mathrm{~h}$ with human full length recombinant Bax. DNA degradation (hypodiploidy) was assessed by flow cytometry. Nuclear morphology in (b) was observed under UV fluorescence microscopy after Hoechst staining (magnification $1000 \times$ ). Per cent in (b) indicate the percentages of hypodiploid nuclei. The data shown are representative of three independent experiments

DNA content (hypodiploidy) was assessed using propidium iodide after cell permeabilization with $2 \%$ saponin (Sigma) in PBS. Cells were analyzed using a FACScan (Becton Dickinson, San Diego, CA, USA).

\section{Transmission electron microscopy}

L. major cells were fixed in $1.25 \%$ glutaraldehyde buffered with $0.1 \mathrm{M}$ sodium phosphate $\left(\mathrm{pH} \mathrm{7.4)}\right.$ for $24 \mathrm{~h}$ at $4^{\circ} \mathrm{C}$, dehydrated with ethanol at $4^{\circ} \mathrm{C}$ and immersed in a $1 / 1$ mixture of propylene oxide and Epon, and 
were embedded in Epon by polymerization at $60^{\circ} \mathrm{C}$ for $48 \mathrm{~h}$. Ultrastructural analysis was performed on a Philips EM 410 electron microscope.

\section{Cell free extract assays}

Cytoplasmic extracts of Jurkat cells, nuclei from CEM cells and the reconstitution of cell-free extracts, were prepared as previously described. ${ }^{38}$ Cytoplasmic extracts from control or staurosporinetreated $L$. major were prepared as follows: cells were washed twice in PBS and incubated on ice for 20 min with Cell Extract Buffer $(50 \mathrm{mM}$ PIPES, pH 7.4, $50 \mathrm{mM} \mathrm{Kcl}, 5 \mathrm{mM}$ EGTA, $2 \mathrm{mM} \mathrm{MgCl} 2,1 \mathrm{mM}$ DTT, $10 \mu \mathrm{M}$ cytochalasin $\mathrm{B}$ and $1 \mathrm{mM}$ PMSF). The suspension was homogenized with a type B pestle. Cells were lysed by forceful passage of the homogenate through a 26-gauge hypodermic needle. Lysis was monitored under a phase contrast microscope. Cell lysate was then centrifuged at $4^{\circ} \mathrm{C}$ for $15 \mathrm{~min}$ at $17000 \times \mathrm{g}$. The clear cytosol was carefully removed and stored at $-80^{\circ} \mathrm{C}$. Cell-free reactions (25 $\mu \mathrm{l})$ comprised $20 \mu \mathrm{l}$ of cytoplasmic extract $(20-30 \mathrm{mg} / \mathrm{ml}$ protein), $1 \mu \mathrm{l}\left(2.10^{5}\right)$ of nuclei and $4 \mu \mathrm{l}$ of Extract dilution Buffer (EDB: $10 \mathrm{mM}$ HEPES, $50 \mathrm{mM} \mathrm{NaCl}, 2 \mathrm{mM} \mathrm{MgCl}$, $5 \mathrm{mM}$ EGTA, $1 \mathrm{mM}$ DTT, $2 \mathrm{mM}$ ATP, $10 \mathrm{mM}$ phosphocreatine and $50 \mu \mathrm{g} / \mathrm{ml}$ creatine kinase). The nuclei were stained with Hoechst $33342(10 \mu \mathrm{M}$, Sigma) and examined by UV fluorescence microscopy (Leika DMRB) (magnification $1000 \times$ ) and nuclear apoptosis was also quantified by staining with the DNAintercaling dye propidium iodide and the DNA content analyzed by flow cytometry. Cleavage of nuclear PARP and ICAD ${ }^{40}$ was also assessed in the cell-free system as described above. After incubation with cytoplasmic extract for $60 \mathrm{~min}$, nuclei were lysed in SDS lysis buffer (125 mM Tris- $\mathrm{HCl} \mathrm{pH} 6,8$, SDS 4\%, Glycerol 10\%) and loaded on acrylamid gel for Western blots using a mouse monoclonal anti-PARP (PharMingen, San Diego, CA, USA) and a rabbit polyclonal anti-ICAD (PharMingen). Recombinant PARP was purchased from R\&D System (Mineapolis, MN, USA).

\section{Immunofluorescence}

L. major cells were stained with the mitochondrion-selective dye MitoTracker green $\mathrm{FM}^{\mathrm{TM}}$ ( $3 \mu \mathrm{M}$, Molecular Probes). Cells were then fixed in 3\% (w/v) paraformaldehyde in PBS for $10 \mathrm{~min}$. The fixed cells were washed three times in PBS for $10 \mathrm{~min}$ each followed by permeabilization in $0.15 \%(\mathrm{v} / \mathrm{v})$ Triton X-100 in PBS for $15 \mathrm{~min}$. The cells were then incubated for $60 \mathrm{~min}$ in blocking buffer ( $2 \%$ bovine serum albumin in PBS) followed by incubation overnight at $4^{\circ} \mathrm{C}$ with rabbit polyclonal antibody raised against yeast cytochrome $c^{42}$ (kindly provided by Dr. R Kluck, La Jolla Institute for Allergy and Immunology, San Diego, USA) diluted 1/100 in blocking buffer. The cells were then washed three times at 10 min each in blocking buffer followed by $4 \mathrm{~h}$ incubation with TRITC-labeled goat anti-rabbit antibody (1/200). The cells were then washed three times at $10 \mathrm{~min}$ each and examined under a Leika DMRB fluorescence microscope (magnification $1500 \times$ ).

\section{Isolation of L. major mitochondria}

Mitochondria vesicles were isolated by hypotonic lysis and Percoll. ${ }^{56}$ All procedures were carried out at $4^{\circ} \mathrm{C}$. L. major were harvested, washed with PBS containing $20 \mathrm{mM}$ glucose, and suspended in hypotonic lysis buffer ( $1 \mathrm{mM}$ Tris- $\mathrm{HCl}, \mathrm{pH} 8.0,1 \mathrm{mM}$ EDTA) at $2.10^{9}$ cells $/ \mathrm{ml}$. The suspension was homogenized with five strokes of a type $B$ pestle in an all-glass Kontes homogenizer. Cells were lysed by forceful passage of the homogenate through a 26-gauge hypodermic needle. Lysis was monitored microscopically. Sucrose (2 M stock) was immediately added to the lysate to $0.25 \mathrm{M}$, and the lysate centrifuged at 11500 r.p.m. in a Sorvall SS34 rotor. The pellet was suspended in one-fifth the original lysate volume of STM buffer $(0.25 \mathrm{M}$ sucrose, $20 \mathrm{mM}$ Tris- $\mathrm{HCl}, \mathrm{pH} 8.0,2 \mathrm{mM} \mathrm{MgCl} 2,0.1 \mathrm{mM}$ PMSF). DNase I (Amersham) was added to $40-50$ units $/ \mathrm{ml}$ and the suspension incubated on ice for 30-45 min. The lysate was diluted fivefold with STE-A buffer (0.25 M sucrose, $20 \mathrm{mM}$ Tris- $\mathrm{HCl}$, pH 8.0, 2 mM EDTA, $0.1 \mathrm{mM}$ PMSF) and centrifuged. The pellet of crude mitochondria was resuspended in one-fifth of STE-A, layered on a $20-35 \%$ Percoll gradient, and centrifuged at 24000 r.p.m. in a Beckman SW28 rotor for $45 \mathrm{~min}$. The turbid band of purified mitochondria near the bottom of the tube was withdrawn, washed four times with STE-B $(0.25 \mathrm{M}$ sucrose, $10 \mathrm{mM}$ Tris- $\mathrm{HCl}$, pH 7.5, $1 \mathrm{mM}$ EDTA, $0.1 \mathrm{mM}$ PMSF). The preparations consisted of mitochondrial vesicles of uniform size, essentially free of flagella and other cell debris.

\section{Cytochrome $c$ release assay}

Full length and $\Delta T M$ recombinant Bax (kindly provided by Dr. B Antonsson (Serono International SA, Geneva, Switzerland) and Dr. JC Martinou (Universite de Genève, Geneva, Switzerland) and were produced as previously described. ${ }^{57}$ One hundred $\mu \mathrm{g}$ of mitochondria were resuspended in $200 \mu \mathrm{l}$ of $\mathrm{KCl}$ buffer $(125 \mathrm{mM} \mathrm{KCl}, 0.5 \mathrm{mM}$ EGTA, $5 \mathrm{mM}$ succinate, $10 \mathrm{mM}$ HEPES-KOH, pH 7.4, $4 \mathrm{mM} \mathrm{MgCl}$, $5 \mathrm{mM} \mathrm{Na}_{2} \mathrm{HPO} 4,5 \mu \mathrm{M}$ Rotenon) and incubated at $30^{\circ} \mathrm{C}$ with $400 \mathrm{nM}$ of recombinant bax for 15 or $60 \mathrm{~min}$. The reaction mixtures were centrifuged at $13000 \times g$ for $10 \mathrm{~min}$ at $4^{\circ} \mathrm{C}$. The supernatant fraction corresponding to $5 \mu \mathrm{g}$ of mitochondria was then analyzed by Western blot for the presence of cytochrome $c$ or incubated with isolated mammalian nuclei to study its pro-apoptotic function.

\section{Western blots}

Protein determination was done using the DC Protein Assay (Bio Rad Laboratories, Hercules, CA, USA). Equal amounts of proteins from $L$. major cytoplasmic extract ( $25 \mu \mathrm{g}$ of proteins) were boiled for $5 \mathrm{~min}$ in $2 \times$ Laemmli sample buffer with $2-\beta \mathrm{ME}$ and run on a $4 / 20 \%$ polyacrylamide gel (Bio Rad). Proteins were then transferred to PVDF membrane (Amersham, Orsay, France), and immunoblotted with the rabbit polyclonal antibody raised against Saccaromyces cerevisiae cytochrome $c^{42}$ or the mouse monoclonal anti-Hsp60 antibody (Stressgen, Victoria, Canada) and then visualized using horseradish-peroxidase-conjugated secondary antibodies (Amersham), followed by enhanced chemiluminescence (Amersham).

\section{Standard DNA agarose gel electrophoresis}

DNA was extracted as previously described ${ }^{38}$ and standard agarose gel electrophoresis was performed as described previously. ${ }^{25,26,38}$

\section{Acknowledgments}

We are very grateful to $B$ Antonsson (Serono Pharmaceutical research Institute, Serono International, SA, Geneva, Switzerland) and JC Martinou (Departement de Biologie Cellulaire, Universite de Geneva, Geneva, Switzerland) for providing the recombinant full length and $\triangle T M B a x$ and for helpful discussions; to R Kluck (La Jolla Institute for Allergy and Immunology, San Diego, CA, USA) for providing an anti-yeast cytochrome $c$ antibody; to. YJ-F Garin (Hopital Saint Louis, France) for providing L. major, and to G Kroemer and S Susin (Villejuif, France) for providing an anti-mammalian AIF antibody. EMI-U 9922 is supported by 
Institut National de la Sante et de la Recherche Medicale (INSERM) and Universite Paris 7, and by grants from Agence Nationale de Recherches sur le Sida (ANRS), Ensemble contre le Sida (ECS), Fondation pour la Recherche Medicale (FRM), Etablissement Francais des Greffes (to JC Ameisen). D Arnoult was supported by doctoral fellowships from Delegation Generale de l'Armement (DGA) and FRM and K Akarid by a post-doctoral fellowship from ECS.

\section{References}

1. Jacobson MD, Weil M and Raff MC (1997) Programmed cell death in animal development. Cell 88: 347-354

2. Vaux DL and Korsmeyer J (1999) Cell death in development. Cell 96: 245-254

3. Meier P, Finch A and Evan G (2000) Apoptosis in development. Nature 407: $796-801$

4. Hengartner M (2000) The biochemistry of apoptosis. Nature 407: 770-776

5. Horvitz HR (1999) Genetic control of programmed cell death in the nematode Caenorhabditis elegans. Cancer Res 59: (Suppl). 11701-11706

6. Thornberry NA and Lazebnik Y (1998) Caspases: enemies within. Science 281: $1312-1316$

7. Green DR (2000) Apoptotic pathways: Paper wraps stone blunt scissors. Cell 102: $1-4$

8. Gross A, McDonnell JM and Korsmeyer SJ (1999) Bcl-2 family members and the mitochondria in apoptosis. Genes Dev. 13: 1899-1911

9. Martinou JC and Green D (2001) Breaking the mitochondrial barrier. Nature Reviews Mol. Cell. Biol. 2: 63-67

10. Zamzami N and Kroemer G (2001) The mitochondrion in apoptosis: how Pandora's box opens. Nature Rev. Mol. Cell. Biol. 2: 67-71

11. Xiang J, Chao DT and Korsmeyer SJ (1996) Bax-induced cell death may not require ICE-like proteases. Proc. Natl. Acad. Sci. USA 93: 14559-14563

12. Quignon F, De Bels F, Koken M, Feuteun J, Ameisen JC and de Thé H (1998) PML induces a novel caspase-independent death process. Nat. Genet. 20:259265

13. Vercammen D, BrouckaertG, Denecker G, Van de Craen M, Declercq W, Fiers W and Vandenabeele $P$ (1998) Dual signaling of the Fas receptor: initiation of both apoptotic and necrotic cell death pathways. J. Exp. Med. 188: 919-930

14. Chautan M, Chazal G, Cecconi F, Gruss P and Golstein P (1999) Interdigital cell death can occur through a necrotic and caspase-independent pathway. Curr. Biol. 9: 967-970

15. Holler N, Zaru R, Micheau O, Thome M, Attinger A, Valitutti S, Bodmer JL, Schneider P, Seed Band TschoppJ(2000)Fas triggers an alternative caspase 8independent cell death pathway using kinase RIP as effector molecule. Nat. Immunol. 1: 489-495

16. Sperandio S, deBelle I and Bredesen D (2000) An alternative non apoptotic form of programmed cell death. Proc. Natl. Acad. Sci. USA 97: 14376-14381

17. Ameisen JC (1996) The origin of programmed cell death. Science 272: 1278 1279

18. Umansky SR (1982) The genetic program of cell death: hypothesis and some applications: transformation, carcinogenesis, ageing. J. Theor. Biol. 97: $591-$ 602

19. Raff MC (1992) Social controls on cell survival and cell death. Nature 356: $397-$ 400

20. Evan GA (1994) Old cells never die, they just apoptose. Trends Cell. Biol. 4: $191-192$

21. Vaux DL, Haeker G and Strasser A (1994) An evolutionary perspective on apoptosis. Cell. 76: $777-779$

22. Steller H(1995) Mechanisms and genes of cellular suicide. Science 267: $1445-$ 1449

23. Ameisen JC (1998) The evolutionary origin and role of programmed cell death in single celled organisms: a new view of executioners, mitochondria, hostpathogen interactions, and the role of death in the process of natural selection. In When cells die, R Lockshin, ZZakeriand JTilly, (eds) (New York: Wiley-Liss, Inc.) pp. 3-56

24. Cornillon S, Foa C, Davoust J, Buonavista N, Gross JD and Golstein P (1994) Programmed cell death in Dictyostelium. J. Cell Sci. 107: 2691-2704
25. Ameisen JC, Idziorek T, Billaut-Mulot O, Loyens M, Tissier JP, Potentier A and Ouaissi MA (1995) Apoptosis in a unicellular eukaryote (Trypanosoma cruzi): implications for the evolutionary origin and role of programmed cell death in the control of cell proliferation, differentiation and survival. Cell Death Differ. 2: 285300

26. Welburn SC, Dale C, Ellis D, Beecroft R and Pearson TW (1996) Apoptosis in procyclic Trypanosoma brucei rhodesiense in vitro. Cell Death Differ. 3: 229236

27. Moreira MEC, DelPortillo HA, Milder RV, Balanco JM and Barcinski MA (1996) Heat shok induction of apoptosis in promastigotes of the unicellular organism Leishmania amazonensis. J. Cell. Physiol. 167: 305-313

28. Christensen ST, Wheatley DN, Rasmussen MI and Rasmussen L (1995) Mechanisms controlling death, survival and proliferation in a model unicellular eukaryote Tetrahymena thermophila. Cell Death Differ. 2: 301-308

29. Vardi A, Berman-Frank I, Rozenberg T, Hadas O, Kaplan A and Levine A (1999) Programmed cell death of the dinoglagellate Peridinium gatunense is mediated by $\mathrm{CO}_{2}$ limitation and oxidative stress. Curr. Biol. 9: 1061-1064

30. Olie RA, Durrieu F, Cornillon S, Loughran G, Gross J, Earnshow WC and Golstein P (1998) Apparent caspase independence of programmed cell death in Dictyostelium. Curr. Biol. 8: 955-958

31. Sogin ML (1991) Early evolution and the origin of eukaryotes. Curr. Opin. Genet. Dev. 1: $457-463$

32. Doolittle RF, Feng DF, Tsang S, Cho G and Little E (1996) Determining divergence times of the major kingdoms of living organisms with a protein clock. Science 271: $470-477$

33. Nagata S (2000) Apoptotic DNA fragmentation. Exp. Cell. Res. 256: 12-18

34. Savill J and Fadok V (2000) Corpse clearance defines the meaning of cell death. Nature 407: $784-788$

35. Weil M, Jacobson MD, Coles HSR, Davies TJ, Gardner RL, Raff KD and Raff MC (1996) Constitutive expression of the machinery for programmed cell death. J. Cell. Biol. 133: 1053

36. Kerr JFR, Willie AH and Currie AR (1972) Apoptosis: a basic biological phenomenon with wide-ranging implications in tissue kinetics. Br. J. Cancer 26 : $239-257$

37. Wang KKW (2000) Calpain and caspases: can you tell the difference? Trends Neurosci. 23: 20

38. Martin SJ, Newmeyer DD, Mathias S, Farschon DM, Wang HG, Reed JC, Kolesnick RN and Green DR (1995) Cell-free reconstitution of Fas-, UV radiationand ceramide-induced apoptosis. EMBO J. 14: 5191-5200

39. Lazebnik YA, Kaufmann SH, Desnoyers S, Poirier GG and Earnshaw WC (1994) Cleavage of poly(ADP-ribose) polymerase by a proteinase with properties like ICE. Nature 371: $346-347$

40. Lechardeur D, Drzymala L, Sharma M, Zylka DK, R, Pacia J, Hicks C, Usmani N, Rommens JM and Lukacs GL (2000) Determinants of the nuclear localization of the heterodimeric DNA fragmentation factor (ICAD/CAD). J. Cell. Biol. 150: $321-334$

41. Sakahira H, Enari M and Nagata S (1999) Functional differences of two forms of the inhibitor of caspase- activated DNase, ICAD-L, and ICAD-S. J. Biol. Chem. 274: $15740-15744$

42. Kluck RM, Ellerby LM, Ellerby HM, Naiem S, Yaffe MP, Margoliash E, Bredesen D, Mauk AG, Sherman F and Newmeyer D (2000) Determinants of cytochrome C pro-apoptotic activity. The role of lysine 72 trimethylation. J. Biol. Chem. 275: $16127-16133$

43. Lorenzo H, Susin S, Penninger J and Kroemer G (1999) Apoptosis inducing factor (AIF): a phylogenetically old, caspase-independent effector of cell death. Cell Death Differ. 6: 516-524

44. Arnoult D, Tatischeff I, Estaquier J, Girard M, Sureau F, Tissier JP, Grodet A, Dellinger M, Traincard F, Kahn A, Ameisen JC and Petit PX (2001) On the evolutionary conservation of the cell death pathway: mitochondrial release of an Apoptosis Inducing Factor during Dictyostelium discoideum cell death. Mol. Biol. Cell 12: (in press)

45. Shimizu S, Shinohara Y and Tsujimoto Y (2000) Bax and Bcl-xL independently regulate apoptotic changes of yeast mitochondria that require VDAC but not adenine nucleotide translocator. Oncogene 19: 4309-4318

46. Roucou X, Prescott M, Devenish RJ and Nagley P (2000) A cytochrome c-GFP fusion is not released from mitochondria into the cytoplasm upon expression of Bax in yeast cells. FEBS Lett. 471: 235-239 
47. Gross A, Pilcher K, Blachly-Dyson E, Basso E, Jockel J, Bassik MC, Korsmeyer SJ and Forte M (2000) Biochemical and genetic analysis of the mitochondrial response of yeast to Bax and Bcl-xL(L). Mol. Cell. Biol. 20: 3125-3136

48. Eskes R, Antonsson B, Osen-Sand A, Montessuit S, Richter C, Sadoul R, Mazzei G, Nichols A and Martinou JC (1998) Bax-induced cytochrome C release from mitochondria is independent of the permeability transition pore but highly dependent on Mg2+ ions. J. Cell. Biol. 143: 217-224

49. Aravind L, Dixit VM and Koonin EV (2001) Apoptotic molecular machinery: vastly increased complexity in vertebrates revealed by genome comparisons. Science 291: $1279-1284$

50. Wolf BB, Golstein JC, Stennicke HR, Beere H, Amarante-Mendes GP, Salvesen GS and Green DR (1999) Calpain functions in a caspase-independent manner to promote apoptotic-like events during platelet activation. Blood. 94: 1683

51. Frame MJ, Mottram JC and Coombs GH (2000) Analysis of the roles of cysteine proteinases of Leishmania mexicana in the host-parasite interaction. Parasitology. 121: 367-377

52. Selzer PM, Pingel S, Hsieh I, Ugele B, Chan VJ, EngelJC, Bogyo M, Russell DG, Sakanari JA and McKerrow JH (1999) Cysteine protease inhibitors as chemotherapy: lessons from a parasite target. Proc. Natl. Acad. Sci. USA. 96: $11015-11022$
53. Wei MC, Zong WX, Cheng EH, Lindsten T, Panoutsakopoulou V, Ross AJ, Roth KA, MacGregor GR, Thompson CB and Korsmeyer SJ (2001) Proapoptotic BAX and BAK: a requisite gateway to mitochondrial dysfunction and death. Science 292: $727-730$

54. Green DR and Beere HM (2000) Apoptosis: Gone but not forgotten. Nature 405: 28-29

55. Freire-de-Lima CG, Nascimento DO, Soares MBP, Bozza PT, Castro-FariaNeto HC, de Mello FG, DosReis GA and Lopes MF (2000) Uptake of apoptotic cells drives the growth of a pathogenic trypanosome in macrophages. Nature 403: 199-203

56. Harris ME, Moore DR and Hajduk SL (1990) Addition of uridines to edited RNAs in trypanosome mitochondria occurs independently of transcription. J. Biol. Chem. 265: $11368-11376$

57. Antonsson B, Conti F, Ciavatta A, Montessuit S, Lewis S, Martinou I, Bernasconi L, Bernard A, Mermod JJ, Mazzei G, Maundrell K, Gambale F, Sadoul R and Martinou JC (1997) Inhibition of Bax channel-forming activity by Bcl-2. Science 277: $370-372$ 